\title{
DAS REICH UND BÖHMEN UM DIE ERSTE JAHRTAUSENDWENDE
}

\author{
FRANZ-REINER ERKENS \\ Philosophische Fakultät, Universität Passau (emeritus) \\ E-mail: reiner.erkens@uni-passau.de
}

\begin{abstract}
The Empire and Bohemia at the Turn of the First Millenium

The review of an often-debated topic relies on a very broad theoretical reevaluation of basic ideas of political power, relationships and concepts. Author proposes a broad summary of the nature of power and government in Central Europe in the given period. The development of the political power in Bohemia and its relation to the imperial world is put in the context of the other Central European states. The relationship is described since its very beginnings in 805 , although the first century gives us only a very limited number of sources. Later contacts such as the church connections, possible regular payments from Bohemia, the possibility of a regular feudal oath are thoroughly described by the author. Bohemia is then understood as a part of a broader imperial world, almost similarly to the other duchies of the Empire. This position could be also beneficial for the building of the political power of the Přemyslids.
\end{abstract}

Keywords: Holy Roman Empire; Bohemia; Central Europe; power; year 1000

Das Reich, das vor mehr als zweihundert Jahren sein Ende fand, ist uns heute nicht allein zeitlich sehr fern gerückt. Auch mental besteht eine große Distanz. Wirkte es im 19. und frühen 20. Jahrhundert noch nach in der Erinnerung und als Orientierungsgröße, hallte es gleichsam wider im Namen des zweiten, des Deutschen Reiches, so wurde es nach der Depravierung der Geschichte durch das „Dritte Reich“ immer weiter aus dem allgemeinen Gedächtnis verdrängt. Immer fremder ist die Epoche der Vormoderne und besonders die Zeit des Mittelalters dabei geworden. Konnte das Hochmittelalter noch vor hundert Jahren in Deutschland mit nationalem Stolz als glanzvoller Höhepunkt der eigenen Geschichte verstanden werden, so hat man von dieser Vorstellung mittlerweile Abschied genommen und wirft nunmehr einen veränderten Blick auf die Vergangenheit, versucht, die Zeit stärker aus ihren eigenen Bedingungen heraus zu verstehen und nicht mehr an nationalstaatlichen Kriterien zu messen oder nach nationalen Vorstellungen zu deuten. Dieses prinzipielle und umfassende Bemühen hat im letzten halben Jahrhundert besondere Bedeutung erlangt für das Verständnis des deutschen Spätmittelalters und des ottonischen Jahrhunderts. Beide Epochen werden heute völlig anders gesehen als noch vor fünfzig Jahren ${ }^{1}$; und besonders grundstürzend ist der Verständniswandel gewesen für jene Zeit, die nunmehr von der Gegenwart durch ein Millennium getrennt ist.

Vgl. für das Spätmittelalter etwa Peter MORAW, Von offener Verfassung zu gestalteter Verdichtung.
Das Reich im späten Mittelalter. 1250 bis 1490. Berlin 1985; DERS., Über König und Reich. Aufsätze
zur deutschen Verfassungsgeschichte des späten Mittelalters, hg. von Rainer Christoph Schwinges. Sig- 
Eine Skizze von den Verhältnissen im Reich um die erste Jahrtausendwende, entworfen aus der neuen Perspektive, muss sich notgedrungen beschränken auf strukturelle Zusammenhänge - nicht allein aus Zeitgründen, sondern auch wegen der keinesfalls opulenten Quellenlage. Weite Bereiche des damaligen Lebens sind nicht oder kaum dokumentiert. Selbst über die gesellschaftliche Oberschicht, über die Fürsten, liegt nur eine begrenzte Zahl an Nachrichten vor, und diese verteilen sich keinesfalls gleichmäßig über das Leben oder den Aktionsraum eines Fürsten. Das Wirken der Herzöge etwa ist wesentlich besser fassbar, sobald es in Beziehung zum Reich oder zum König steht, als bei der Erfüllung der herzoglichen Aufgaben im eigenen Zuständigkeitsbereich ${ }^{2}$. Und dies gilt nicht zuletzt auch für die Herzöge Böhmens ${ }^{3}$, die ebenso wie ihr Herzogtum auf besondere Weise mit dem Reich verbunden waren.

Die Art dieser Verbindung ist gerade in nationalistischen Zeiten heftig und kontrovers sowie aufgeladen mit nationalen Emotionen diskutiert worden. Doch kann diese Diskussion heute übergangen werden - nicht nur, weil, wie gesagt, nationale Kriterien keine Rolle mehr spielen (sollten) bei historischen Interpretationen, sondern mehr noch, weil entgegen älterer Auffassung - die Volkswerdung der Deutschen um 1000 noch gar nicht abgeschlossen war ${ }^{4}$. Die nachfolgenden Betrachtungen gehen daher lediglich von dem Herrschaftsgebilde des Reiches aus, das natürlich einen erheblichen Machtfaktor darstellte und den jüngeren, erst im Entstehen begriffenen Staatswesen östlich der Reichsgrenze an Ressourcen und institutioneller Ausgestaltung überlegen war und für diese daher zwangsläufig zu einem Orientierungspunkt und Gravitationszentrum werden musste.

Die Tatsache, dass dieses Reich - gemessen an modernen Verhältnissen - kaum staatliche Strukturen besaß, ist bekannt und hat immer wieder zu der Frage geführt, ob es überhaupt als Staat bezeichnet werden könne. An dieser Stelle braucht dieses terminologische Problem nicht weiter zu interessieren, zumal es auch die übrigen Herrschaftsverbände des früheren Mittelalters betrifft und Lösungsversuche mit unterschiedlichen Ergebnissen vorgetragen worden sind ${ }^{5}$ : Konnte auf der einen Seite vom „Staat des hohen

maringen 1995, sowie Erich MEUTHEN, Das 15. Jahrhundert. München/Wien 1980 (5. Aufl. 2012 von Claudia MÄRTL), für die Ottonenzeit Gerd ALTHOFF - Hagen KELLER, Die Zeit der späten Karolinger und der Ottonen. Krisen und Konsolidierungen 888-1024. Stuttgart 2008, sowie Gerd ALTHOFF, Spielregeln der Politik im Mittelalter. Kommunikation in Frieden und Fehde. Darmstadt 2014, und hieraus bes. das Nachwort auf S. 361-401. Mittelalterliche Verfassungsgeschichte und Spielregeln der Politik: ein Nachwort; aber auch, weil auf ungelöste Probleme verweisend, DERS., Spielregeln symbolischer Kommunikation und das Problem der Ambiguität, in: Barbara Stollberg-Rilinger u. a. (Hgg.), Alles nur symbolisch? Bilanz und Perspektiven der Erforschung symbolischer Kommunikation. Köln/Weimar/Wien 2013, S. 35-51, und DERS., Das hochmittelalterliche Königtum. Akzente einer unabgeschlossenen Neubewertung, in: FMS 45 (2011), S. 77-98.

2 Vgl. Franz-Reiner ERKENS, Herzog, Herzogtum, in: Handwörterbuch zur deutschen Rechtsgeschichte 2 (2011), S. 993-1004, bes. 999.

3 Vgl. Ivan HLAVÁČEK, Die Itinerare der böhmischen Herrscher bis zum Jahre 1253 aus verwaltungsgeschichtlicher Sicht, in: Sáša Dušková (Hg.), Folia Diplomatica. Bd. 1. Brno 1971, S. 113-127, bes. 116: „Über böhmische Herrscher des 9. und 10. Jahrhunderts haben wir nur wenige sichere Nachrichten".

4 Vgl. Carlrichard BRÜHL, Deutschland - Frankreich. Die Geburt zweier Völker. Köln/Wien 1995; Joachim EHLERS, Die Entstehung des deutschen Reiches. München 2012.

5 Vgl. zum folgenden Heinrich MITTEIS, Der Staat des hohen Mittelalters. Grundlinien einer vergleichenden Verfassungsgeschichte des Lehnszeitalters. Darmstadt ${ }^{9} 1974$ [erstmals Weimar 1940]; Gerd ALTHOFF, Die Ottonen. Königsherrschaft ohne Staat. Stuttgart 2000 u. ö., und das neueste Plädoyer für den mittelalterlichen Staat Walter Pohl - Veronika Wieser (Hgg.), Der frühmittelalterliche Staat - 
Mittelalters“ die Rede sein, so sprach man auf der anderen von „Königsherrschaft ohne Staat". Für die weiteren Ausführungen ist allein die nach modernem Verständnis überaus spürbare Unstaatlichkeit der mittelalterlichen Staatswesen von Bedeutung, gleichgültig, wie man diese auch benennen mag. Diesen unstaatlichen Zustand haben die mittelalterlichen Herrscher als normal und keinesfalls als Manko empfunden, da sie in anderen als anstaltsstaatlichen oder nationalstaatlichen Traditionen standen.

Ihr Staatswesen wurde entscheidend vom $\operatorname{Adel}^{6}$ (und der hohen Geistlichkeit, die mit wenigen Ausnahmen auch adlig war) mitgetragen, von einem Adel, der seine gesellschaftliche Stellung keinesfalls allein dem König verdankte, besonders in den fürstlichen Kreisen über eine große Eigenständigkeit und ein entsprechendes Selbstbewusstsein verfügte und daher eine Teilhabe am Reich, eine Beteiligung an der Herrschaft beanspruchte und besaß. Dualistisch, so hat man schon längst betont, sind daher Reichsordnung und Herrschaftssystem im Mittelalter gewesen, König und Adel trugen das Reich gemeinsam. In dieser Adelsgesellschaft spielten - neben praktischen Machtmitteln wie Besitz, wirtschaftliche Einkünfte und (militärische) Gefolgschaft, Größen, die keinesfalls unabhängig voneinander waren - Ehre, Ansehen, Würde und Einfluss eine erhebliche Rolle. Dies waren Kriterien, die ebenfalls für den König von großer Wichtigkeit gewesen sind. Der König vereinte zweifellos die meisten Machtmittel in seinen Händen auf der Basis des Familienbesitzes und des Reichsguts, besaß die höchste Autorität, genoss die Unterstützung der Geistlichkeit und die Zustimmung des Herrschaftsverbandes, der ihn gewählt hatte. Über unumschränkte Macht jedoch verfügte er, wie gesagt, nicht. Er bedurfte - angesichts des weitgehenden Fehlens von raumdurchdringenden Herrschaftsstrukturen und herrschaftsintensivierenden Verwaltungsinstrumenten - der Mitwirkung des Adels und der Geistlichkeit bei der Ausübung seiner Herrschaft. Diese hatten nicht nur die Pflicht, sondern auch das Recht, den König zu beraten ${ }^{7}$ und besaßen daher die Möglichkeit, eigene Interessen gegenüber dem König zu artikulieren. Eine zu starke Einengung des Beraterkreises auf nur wenige Personen oder gar auf eine graue Eminenz führte daher zu Opposition und (bewaffnetem) Widerstand ${ }^{8}$, die ebenfalls provoziert werden konnten, wenn Adlige oder Adelskreise ihre Interessen und Rechte wirklich oder auch nur vermeintlich missachtet glaubten. Deshalb war ein Gutteil der königlichen Herrschaftspraxis, die natürlich grundsätzlich der Verwirklichung von Recht und Gerechtigkeit zu dienen und Schutz nach außen und innen zu garantieren hatte ${ }^{9}$, darauf ausgerichtet, ausgleichend auf divergierende Adelsinteressen zu wirken. Moderator, nicht

Europäische Perspektiven. Wien 2009, sowie Stuart Airlie - Walter Pohl - Helmut Reimitz (Hgg.), Staat im frühen Mittelalter. Wien 2006.

6 Zu diesem vgl. Werner HECHBERGER, Adel, Ministerialität und Rittertum im Mittelalter. München 2004, und DERS., Adel im fränkisch-deutschen Mittelalter. Zur Anatomie eines Forschungsproblems. Ostfildern 2005.

7 Vgl. Gerd ALTHOFF, Kontrolle der Macht. Formen und Regeln politischer Beratung im Mittelalter. Darmstadt 2016.

8 Vgl. Franz-Reiner ERKENS, Fürstliche Opposition in ottonisch-salischer Zeit. Überlegungen zum Problem der Krise des frühmittelalterlichen Reiches, in: Archiv für Kulturgeschichte 64 (1982), S. 307-370.

9 Vgl. Franz-Reiner ERKENS, König, in: Handwörterbuch zur deutschen Rechtsgeschichte 3 (2013), S. $3-18$, bes. $10 \mathrm{ff}$. 
nur höchster Richter und oberster Heerführer hatte der Herrscher zu sein, um den für den Erfolg seiner Herrschaft nötigen Konsens herzustellen ${ }^{10}$.

Ein solch oszillierendes Gebilde unterschiedlicher Kräfte und Interessen, wie es das Reich war, verlangte viel Aufmerksamkeit und erklärt zugleich, warum der König angesichts seiner institutionellen Möglichkeiten nur Macht in den Verhältnissen, nicht jedoch über die Verhältnisse besaß. Trotzdem ist er aber nie nur ein einfacher primus inter pares gewesen $^{11}$, denn zweifellos wurde sein Vorrang anerkannt, galt das Königtum doch unbestritten als eine von Gott eingerichtete Institution und der König, auch wenn er von den Großen erhoben wurde, als von Gott auserwählt. Weiter ausgestaltet und gefestigt wurde diese herausgehobene Stellung durch die kirchliche Weihe und besonders durch die Salbung, die seit Otto dem Großen auch im Reich bei der Übernahme der Königsherrschaft üblich geworden war, den Monarchen zu einem Gesalbten des Herrn (christus Domini) machte, mit einer eigenen sakralen Aura umgab, ihm seine besondere religiöse Verantwortung einschärfte und die Stellung als irdischer Sachwalter Gottes (vicarius Christi) betonte ${ }^{12}$. Eine weitere Steigerung erfuhr diese Exklusivität durch die ebenfalls seit Otto dem Großen dauerhaft mit dem ostfränkisch-deutschen Königtum verbundene Kaiserwürde.

Diese herrscherliche Sakralität, die in einer weit ins Altertum zurückreichenden Tradition stand und zugleich ein globales Phänomen der Vormoderne darstellt, wurde begründet durch die besondere Nähe des Herrschers zu Gott, als dessen auserwählter Stellvertreter und Sachwalter der König und Kaiser galt, dem eine religiöse Verantwortung zufiel als Schützer der Christenheit und Schirmherr des Papstes, aber auch als Bewahrer und Bewirker von Gerechtigkeit. Bei dieser Aufgabe hatte er nämlich die Gerechtigkeit Gottes zu verwirklichen und den Menschen ein Leben zu ermöglichen, das ihr Seelenheil nicht gefährdete. Zugleich sollte er selbst ein an der christlichen Morallehre orientiertes Leben führen und den Menschen dadurch als Vorbild den rechten Pfad der seelenheilsichernden Tugend weisen. Dadurch eignete dem Herrscher, ohne selbst Priester zu sein, eine sazerdotale Qualität, auf welche die Bischöfe bei der Krönung des Königs hinwiesen, wenn sie ihn daran erinnerten, ein Teilhaber ${ }^{13}$, ein particeps, ihres Amtes zu sein.

Um das Jahr 1000 ist nicht nur ein Höhepunkt dieses sakralen Königtums erreicht worden, das damals in seinem engen Gottesbezug auch in mehreren Buchminiaturen zur Anschauung gebracht worden ist ${ }^{14}$, sondern es fand offenkundig in dem geistlich erzogenen, bistumsgründenden, Synoden abhaltenden und an Kirchweihen äußerst interessierten Heinrich II. eine ideale Verkörperung ${ }^{15}$. Als Bruder der Mönche, ja, ge-

10 Vgl. Bernd SCHNEIDMÜLLER, Konsensuale Herrschaft. Ein Essay über Formen und Konzepte politischer Ordnung im Mittelalter, in: Paul-Joachim Heinig u. a. (Hgg.), Reich, Regionen und Europa in Mittelalter und Neuzeit. Festschrift für Peter Moraw. Berlin 2000, S. 53-87.

11 Vgl. Hagen KELLER, in: Ders. - Althoff, Die Zeit der späten Karolinger, S. 147.

12 Vgl. Franz-Reiner ERKENS, Herrschersakralität im Mittelalter. Von den Anfängen bis zum Investiturstreit. Stuttgart 2006.

13 Ordo ad regem benedicendum quando novus a clero et populo sublimatur in regem, hg. von Cyrille Vogel - Reinhard Elze, Le Pontifical romano-germanique du dixième siècle. Bd. 1: Le Texte. Città del Vaticano 1963, S. 257 (Nr. LXXII 22).

14 Vgl. ERKENS, Herrschersakralität, Kap. 6 und bes. S. 176-187.

15 Vgl. Franz-Reiner ERKENS, Frommer Mönchskönig, sakraler Christusvikar und heiliger Kaiser. Heinrich II., in: Norbert Jung - Holger Kempkens (Hgg.), Gekrönt auf Erden und im Himmel - das 
radezu als Mönchskönig ${ }^{16}$ konnte der letzte Liudolfinger verstanden werden, als Kollege - simpnista und coepiscopus ${ }^{17}$ - der Bischöfe ${ }^{18}$, der zugleich den Königsdienst der Geistlichkeit zu intensivieren wusste ${ }^{19}$. In gewisser Weise ist damals ein Höhepunkt und die volle Ausgestaltung erreicht worden für den schon längst bestehenden und beiden Seiten nutzbringenden Bund von Gesalbten, in dem der König Kirchenhoheit und Investiturrecht nahezu unbestritten ausübte, die Kirchen von den reichen Zuwendungen und dem Schutz des Herrschers profitierten und die hohe Geistlichkeit im Dienst für das Reich Ansehen und Einfluss gewann ${ }^{20}$. Getragen und gefestigt worden ist dieses ,System durch einen breiten Konsens der Beteiligten, der sich später noch nicht einmal im Investiturstreit rasch auflöste ${ }^{21}$.

Die hohe Geistlichkeit stellte daher insgesamt eine zuverlässige Stütze der ottonischsalischen Herrschaft dar, während der schwertführende und selbstbewusste Adel ein eher unruhiges Element bildete ${ }^{22}$. Doch bedeutete dies, auch wenn es zu langanhaltenden Auseinandersetzungen und bewaffneten Widerständen kommen konnte, keine prinzipielle Opposition gegen Königtum und Reichsherrschaft, denn der Herrscher war nicht nur, wie es später heißen sollte, ein Mehrer des Reiches, sondern auch ein Mehrer von Einkünften und Ansehen. Der Einsatz für König und Reich konnte sich für den Adel mithin ebenso lohnen wie für die Geistlichkeit, und dies um das Jahr 1000 um so mehr, als damals die königliche Verfügungsgewalt über die hohen Reichswürden noch nicht allzu sehr eingeschränkt war und z. B. die meisten Herzogtümer noch nicht erblich waren und zur Rangsteigerung einer Fürstenfamilie dienen konnten. Adel und König profitierten gegenseitig also ebenso von einem Miteinander wie Bischöfe und König, wenn das zwischen König und Fürsten vorhandene Konfliktpotential auch zweifellos größer war.

Vor dem Hintergrund einer Herrschaftsordnung, die charakterisiert ist durch unterschiedliche Gruppenbindungen und Interessenverbände, fehlende Verwaltungsorgane und mangelnde institutionelle Verdichtung, die stark geprägt ist vom Rangdenken, von Ehr- und Würdevorstellungen und die Anerkennung von Autorität erwartet, weniger jedoch den machtvollen Befehl, wenn man so will: weniger ein ,Durchregieren' bis in die letzten Winkel des Reiches, vor dem Hintergrund einer solch flexiblen Herrschaftsordnung ist auch das Verhältnis zu den Regionen östlich der Reichsgrenze zu betrachten. Reiche und Staatswesen mit entwickeltem Machtpotential ziehen herrschaftlich-politisch

heilige Kaiserpaar Heinrich II. und Kunigunde. Münsterschwarzach 2014, S. 20-27, und Heinz WOLTER, Die Synoden im Reichsgebiet und in Reichsitalien von 916 bis 1056. Paderborn 1988, S. 214-312.

16 Vgl. Joachim WOLLASCH, Kaiser und Könige als Brüder der Mönche. Zum Herrscherbild in liturgischen Handschriften des 9. bis 11. Jahrhunderts, in: DA 40 (1984), S. 1-20 und Hartmut HOFFMANN, Mönchskönig und „rex idiota“. Studien zur Kirchenpolitik Heinrichs II. und Konrads II. Hannover 1993.

17 Thietmari Merseburgensis episcopi Chronicon (Scriptores rerum Germanicarum. Nova series 9), hg. von Robert HOLTZMANN. Berlin 1935, S. 321 (VI 38) und 294 (VI 18).

18 Vgl. Stefan WEINFURTER, Kollegen des Königs. Die Bischöfe im Reich vor 1000 Jahren, in: Christoph Stiegemann - Martin Kroker (Hgg.), Für Königtum und Himmelreich. 1000 Jahre Bischof Meinwerk von Paderborn. Regensburg 2009, S. 30-38, bes. 32.

19 Vgl. Franz-Reiner ERKENS, „Nach Art der himmlischen Martha“. Bischof Meinwerk im Dienst des Königs, in: ebd. S. 58-73, bes. $63 \mathrm{f}$.

20 Vgl. Claudia ZEY, Der Investiturstreit. München 2017, S. 13-16, bes. 15 f.

21 Vgl. ebd. S. 32 und 88 sowie 106.

22 Vgl. Anm. 8. 
weniger entwickelte Regionen ihres territorialen Vorfeldes oft in ihre Einflußsphäre ${ }^{23}$. So ist es auch vom fränkischen Reich aus nach Osten in den slawischen Raum hinein geschehen und in Tradition wie Kontinuität davon ebenfalls vom ostfränkisch-ottonischsalischen Reich aus, wobei Sachsen und Bayern eigene Ausgangszonen für diese Bewegung bildeten. Lukrativ waren dabei zunächst die Tribute ${ }^{24}$, die aus dem östlichen Vorfeld des Reiches gezogen werden konnten. Aus der Bedeutung solcher Zahlungen erklärt sich etwa auch - zumindest zum Teil - Thietmars von Merseburg Ärger über die Entlassung des Polenherzogs Bolesław Chrobry aus der Tributpflicht durch Otto III., ein freilich weiterreichender Unmut, den der Bischof in die bekannten Worte kleidete ${ }^{25}$ : „Gott möge dem Kaiser verzeihen, dass er aus einem Tributpflichtigen einen Herrn gemacht hat.“

In dem breiten, östlich der Reichsgrenze gelegenen Interessenraum des ottonischen Königtums, des sächsischen wie bayerischen Adels und der nicht nur, aber doch auch von Missionswillen bewegten Geistlichkeit war der Prozess der monarchischen Herrschaftsbildung, man kann auch sagen: der Staatswerdung, bei weitem noch nicht so weit vorangekommen wie im Reich und befand sich in verschiedenen Regionen in einem unterschiedlichen Zustand der Entwicklung. Ganz grob lassen sich um das Jahr 1000 vier Zonen unterscheiden: die bereits stärker christianisierten, sich herrschaftlich zunehmend auf eine Fürstenfamilie konzentrierenden Räume Ungarns, Polens und Böhmens einschließlich Mährens sowie der noch stark im Heidentum verharrende, politisch zersplitterte Bereich zwischen südlicher Ostseeküste und Elbe. Während dieser Bereich ${ }^{26}$ Zeichen der Bedeutung einer monarchischen Herrschaft für das Gelingen der Staatswerdung - im weiteren Verlauf der Geschichte keine Eigenständigkeit gewann, sondern in die hier entstehenden Territorien des Reichs integriert wurde, entwickelten sich Böhmen, Polen und Ungarn zu Königreichen europäischen Zuschnitts - dies allerdings unterschiedlich rasch und unter unterschiedlichen Bedingungen. Am schnellsten ging dies mit Förderung von Papst und Kaiser in Ungarn ${ }^{27}$, am längsten dauerte es in Polen, wo zwar bereits im 11. Jahrhundert, freilich ohne anhaltenden Erfolg und mit spürbarer Spitze gegen das Reich, nach der Königskrone gegriffen worden ist, wo es aber erst um 1300 (1295 beginnend und seit 1320 unumkehrbar) zur Errichtung eines Königtums kam ${ }^{28}$.

${ }^{23}$ Vgl. dazu wie auch zum folgenden Franz-Reiner ERKENS, Konrad II. Herrschaft und Reich des ersten Salierkaisers. Darmstadt 1998, S. 150-157, bes. 154 f., sowie Peter MORAW, Das Mittelalter, in: Friedrich Prinz (Hg.), Deutsche Geschichte im Osten Europas. Böhmen und Mähren. Berlin 1993, S. 23-178, bes. 30-50 und hier insbesondere 44-49.

${ }^{24}$ Vgl. Ulrich MATTEJIET, Tribut III. Hoch- und Spätmittelalter, in: Lexikon des Mittelalters 8 (1997), Sp. 987.

25 Thietmari Chronicon, S. 232 (V 10: Deus indulgeat imperatori, quod tributarium faciens dominum...).

26 Vgl. Eberhard BOHM, Elb- und Ostseeslaven, in: Lexikon des Mittelalters 3 (1986), Sp. 1779-1788, bes. 1786 f., sowie Wolfgang BRÜSKE, Untersuchungen zur Geschichte des Lutizenbundes. Deutsch-wendische Beziehungen des 10.-12. Jahrhunderts. Köln/Wien 1983; Herbert LUDAT, Elbslaven und Elbmarken als Problem der europäischen Geschichte, in: DERS., Slaven und Deutsche im Mittelalter. Ausgewählte Aufsätze zu Fragen ihrer politischen, sozialen und kulturellen Beziehungen. Köln/Wien 1982, S. 1-13 [erstmals 1968], bes. 5 f.; Wolfgang H. FRITZE, Das Vordringen deutscher Herrschaft in Teltow und Barnim, in: DERS., Frühzeit zwischen Ostsee und Donau. Ausgewählte Beiträge zum geschichtlichen Werden im östlichen Mitteleuropa vom 6. bis zum 13. Jahrhundert, hg. von Ludolf Kuchenbuch und Winfried Schich. Berlin 1982, S. 295-374 [erstmals 1971], bes. 372 f.; Christian LÜBKE, Das östliche Europa. München 2004, S. 276-289.

27 Vgl. Thomas VON BOGYAY, Grundzüge der Geschichte Ungarns. Darmstadt 1977, Kap. IV-VI.

28 Vgl. Gotthold RHODE, Kleine Geschichte Polens. Darmstadt 1965, Kap. I-IV; Jörg K. HOENSCH, Geschichte Polens. Stuttgart 1998, Kap. 1.2, 1.3 und 1.5.1; Percy Ernst SCHRAMM, Das polnische Kö- 
Polen und Ungarn, von den Kaisern zunächst in besonderer Form ihrem Herrschaftsbereich zugeordnet ${ }^{29}$, sind, stabilisiert durch eigene Kirchenprovinzen, letztendlich rasch aus diesem imperialen Gefüge hinausgeglitten. Der hier vorrangig interessierende Herrschaftsraum Böhmen hingegen nahm eine andere Entwicklung. Er blieb dem Reich dauerhaft verbunden, obwohl sich die böhmische Herzogsherrschaft ebenfalls, und zwar mit Unterstützung der Beherrscher des Reichs, zum Königtum steigerte und Böhmen seit 1198 ein Königreich war ${ }^{30}$.

Die Gründe für diese besondere Entwicklung sind unterschiedlicher Art. Anders als Polen lag Böhmen damals dem Reich unmittelbar benachbart und ist trotz der Grenzen schützender Höhenzüge recht einfach zu erreichen gewesen. Im Vergleich dazu war die Donau-Theiß-Ebene durch den Aufstieg der sächsischen Liudolfinger zur Königswürde deutlich an die Peripherie gerückt, da Franken und Sachsen nunmehr die eigentliche Basis des Königtums bildeten ${ }^{31}$. Zudem - und nun erfolgt der Wechsel in den Bereich der historischen Gründe - waren die Ungarn über ein gutes halbes Jahrhundert hinweg die Reichsfeinde schlechthin, die bei ihren Raubzügen das Land plagten und plünderten ${ }^{32}$. In dieser Zeit gab es keine Entwicklung friedlicher Beziehungen. Diese setzte erst nach 955, nach der ungarischen Niederlage auf dem Lechfeld, ein, führte dann aber schon ein knappes halbes Jahrhundert später zur Etablierung eines christlichen Königtums. Und in eben diesem Zeitraum bahnten sich auch erst Beziehungen zu Polen an.

Ganz anders dagegen gestaltete sich das Verhältnis zwischen dem ostfränkischen Reich und dem böhmischen Raum. Geographische Nähe paarte sich hier mit historischer Tiefe und ließ ein Beziehungsnetzwerk entstehen. Dieses ist zwar nicht in Einzelheiten erkennbar, reicht aber, soweit es sich erfassen lässt, immerhin bis in die Zeit Karls des Großen zurück. Natürlich hinterließen vor allem Konflikte und militärische Aktionen Spuren in den Quellen, die sporadisch Nachrichten von böhmisch-fränkischen Kontakten überliefern. 805 etwa sind die Böhmen von den Franken unter Führung des ältesten Sohnes Karls des Großen mehrere Wochen lang verheerend heimgesucht worden ${ }^{33}$. Der Anlass

nigtum. Ein Längsschnitt durch die polnische Geschichte (im Hinblick auf Krönung, Herrschaftszeichen und Staatssymbolik), in: DERS., Kaiser, Könige und Päpste. gesammelte Aufsätze zur Geschichte des Mittelalters. Bd. 4. Teil 2. Stuttgart 1971, S. 570-596 [erstmals 1956], bes. 572-575 und 579 f.

29 Vgl. Gerd ALTHOFF, Otto III. und die neuen Reiche im Osten, in: Keller - Althoff, Die Zeit der späten Karolinger, S. 295-303; Rudolf SCHIEFFER, Christianisierung und Reichsbildungen. Europa 700-1200. München 2013, S. 173 f. und $179 \mathrm{f}$.

30 Vgl. Wolfgang H. FRITZE, Corona regni Bohemiae. Die Entstehung des böhmischen Königtums im 12. Jahrhundert im Widerspiel von Kaiser, Fürst und Adel, in: DERS., Frühzeit zwischen Ostsee und Donau, S. 207-296; Percy Ernst SCHRAMM, Böhmen und das Regnum. Die Verleihungen der Königswürde an die Herzöge von Böhmen (1085/86, 1158, 1198/1203), in: DERS., Kaiser, Könige und Päpste 4/2, S. 517-539, bes. 523-527, 530-535 und 536 f.; Heinrich APPELT, Böhmische Königswürde und staufisches Kaisertum, in: DERS., Kaisertum, Königtum, Landesherrschaft. Gesammelte Schriften zur mittelalterlichen Verfassungsgeschichte, hg. von Othmar Hageneder - Herwig Wolfram. Wien 1988, S. 40-60 [erstmals 1972].

31 Vgl. Josef SEMMLER, Francia Saxoniaque oder Die ostfränkische Reichsteilung von 865/76 und die Folgen, in: DA 46 (1990), S. 337-374.

32 Vgl. VON BOGYAY, Grundzüge der Geschichte Ungarns. Kap. 4; Franz-Reiner ERKENS, Die Salzburger Kirchenprovinz und das Bistum Augsburg im Zeitalter der Ottonen und der frühen Salier (9071046), in: Walter Brandmüller (Hg.), Handbuch der bayerischen Kirchengeschichte. Bd. 1: Von den Anfängen bis zur Schwelle der Neuzeit 1. Kirche, Staat und Gesellschaft. St. Ottilien 1998, S. 133-186, bes. 146, und KELLER, in: Ders. - Althoff. Die Zeit der späten Karolinger, \$\$ 7a, 9a, 11c.

33 Vgl. die Jahrbücher des Fränkischen Reiches unter Karl dem Großen, hg. von Sigurd ABEL, fortgesetzt von Bernhard SIMSON. Bd. 2: 789-814. Leipzig 1883, S. 322-328. Jüngere Darstellungen über die 
für dieses groß angelegte und immerhin mit drei Heeressäulen durchgeführte Unternehmen ist unbekannt und der Erfolg bleibt, abgesehen von den Verwüstungen, zweifelhaft, denn ein Jahr später ist die militärische Expedition, allerdings mit deutlich geringeren Kräften, fortgesetzt oder wiederholt worden - wiederum ohne greifbares Ergebnis, wie der lapidare Bericht der Reichsannalen erkennen lässt, wenn es heißt, dass Heer sei ohne einen schweren Unfall heimgekehrt ${ }^{34}$. Positiveres wusste man offenbar nicht zu vermelden. $\mathrm{Ob}$ die Böhmen damals wirklich unterworfen ${ }^{35}$ oder zumindest auf Dauer tributpflichtig gemacht worden sind, wie Einhard, der Biograph Karls des Großen, behauptet und eine erst im frühen 12. Jahrhundert von Cosmas von Prag formulierte Ansicht nahelegt ${ }^{36}$, lässt sich keinesfalls mit Sicherheit behaupten. Allerdings erschienen Böhmen 822 auf einem Hoftag Ludwigs des Frommen in Frankfurt wie wohl auch schon 815 in Paderborn, da sich unter omnes orientalium Sclavorum primores et legati, die an die Quellen der Pader kamen, wahrscheinlich auch böhmische Große oder Gesandte befanden ${ }^{37}$. Die Einbeziehung des böhmischen Siedlungsraumes in die Einflußspähre des Karolingerreiches ist mithin unverkennbar, Ausgestaltung und Intensität dieser Oberhoheit jedoch lassen sich nicht wirklich greifen. Ein entscheidendes Ereignis für die böhmisch-ostfränkischen Beziehungen war jedoch das Erscheinen von vierzehn böhmischen Großen - die Fuldaer Annalen sprechen von duces - am Hof Ludwigs des Deutschen, die Christen werden wollten und die der König am 13. Januar 845 samt Gefolge taufen ließ $3^{38}$. Nun intensivierten sich zwangsläufig die christlichen Bindungen, die auch von einer nur schwer fassbaren, von Regensburg ausgehenden Mission bestimmt wurden ${ }^{39}$.

Zeit Karls des Großen halten dieses Unternehmen offenbar überhaupt nicht mehr für erwähnenswert. Vgl. Johannes FRIED, Karl der Große. Gewalt und Glaube. Eine Biographie. München 2013; Stefan WEINFURTER, Karl der Große. Der heilige Barbar. München/Zürich 2013.

34 Annales regni Francorum inde ab a. 741. usque ad a. 829, qui dicuntur Annales Laurissenses maiores et Einhardi, hg. von Friedrich KURZE (MGH Scriptores rerum Germanicarum in usum scholarum separatim editi. Bd. 6). Hannover 1895, S. 122 (a. 806: absque ullo gravi incommodo regressa); vgl. ABEL - SIMSON, Jahrbücher des Fränkischen Reiches 2, S. 357.

35 Dies meint Adolf BACHMANN, Geschichte Böhmens. Bd. 1: (bis 1400). Gotha 1899, S. 92 ff., während Hartmut HOFFMANN, Böhmen und das deutsche Reich im hohen Mittelalter, in: Jb. für die Geschichte Mittel- und Ostdeutschlands 18 (1969), S. 1-62, bes. 5-12, differenzierter urteilt; vgl. aber auch Dieter HÄGERMANN, Karl der Große. Herrscher des Abendlandes. München 2000, S. 514, und Wilfried HARTMANN, Karl der Große. Stuttgart 2010, S. 225, die skeptisch bleiben.

36 Einhardi Vita Karoli Magni, hg. von Oswald HOLDER-EGGER (MGH Scriptores rerum Germanicarum in usum scholarum separatim editi. Bd. 25). Hannover/Leipzig 1911, S. 18 (c. 15); Die Chronik der Böhmen des Cosmas von Prag (Cosmae Pragensis Chronica Boemorum), hg. von Berthold BRETHOLZ (Scriptores rerum Germanicarum. Nova series 2). Berlin 1923, S. 93 f. (II 8).

37 Annales regni Francorum, a. 822 und 815, S. 159 (omnium orientalium Sclavorum, id est [...] Beheimorum, Marvanorum, [...]) und 142. Ob unter den multae[..] legationes Sclavorum, die 831 am Hof Ludwigs des Frommen erschienen (Annales de Saint-Bertin, hg. von Félix GRAT - Jeanne VIELLIARD - Suzanne CLÉMENCET. Paris 1964, S. 4 [a. 831]), auch Böhmen waren, lässt sich natürlich nur vermuten, nicht aber mit Sicherheit behaupten.

38 Annales Fuldenses sive Annales regni Francorum orientalis, hg. von Friedrich KURZE (MGH Scriptores rerum Germanicarum in usum scholarum separatim editi. Bd. 7). Hannover 1891, S. 35 (a. 845); vgl. dazu Winfried HARTMANN, Ludwig der Deutsche. Darmstadt 2002, S. 113; Paul MAI, Bemerkungen zur Taufe der 14 böhmischen duces im Jahre 845, in: Beiträge zur Geschichte des Bistums Regensburg 29 (1995), S. 11-18.

39 Vgl. František GRAUS, Böhmen zwischen Bayern und Sachsen. Zur böhmischen Kirchengeschichte des 10. Jahrhunderts, in: Historica 17 (1969), S. 5-42, bes. 7; Egon BOSHOF, Mainz, Böhmen und das Reich im Früh- und Hochmittelalter, in: Archiv für mittelrheinische Kirchengeschichte 50 (1998), S. 11-40, bes. S. 14 . 
Allerdings bedeutete dies kein Ende militärischer Aktionen gegen Böhmen. Von diesen gab es auch weiterhin genügend ${ }^{40}$, doch rückte zunächst der Konflikt mit dem sich bildenden Mährerreich in den Vordergrund ${ }^{41}$, ein heftiger Konflikt, der eine besondere macht-, kirchen- und religionspolitische Dimension besaß ${ }^{42}$, für die weitere böhmische Geschichte aber insofern von Interesse ist, als er die kirchliche Verflechtung zwischen Bayern und dem mährischen Raum veranschaulicht und Mähren schließlich zum böhmischen Herrschaftsgebiet dazugehören sollte (wenn die - was freilich umstritten, aber immerhin doch wahrscheinlich ist - Lage des,Großmährischen Reichs' sich zumindest teilweise mit dem späteren Mähren deckte ${ }^{43}$ ). Immerhin kann es kaum einen Zweifel daran geben, dass die bayerische und insbesondere die Passauer Kirche Mähren als ihr Missionsgebiet betrachtete ${ }^{44}$ und hier aktiv geworden ist, wenn auch vielleicht nicht in dem Maße, wie früher einmal angenommen wurde ${ }^{45}$.

Im 10. Jahrhundert ist dieses Beziehungsgeflecht, das nach Auskunft des Raffelstetter Zollweistums ${ }^{46}$ von 904/906 auch eine merkantile, nur ausnahmsweise bezeugte Dimension besaß, weiter ausgestaltet worden, als die Königsherrschaft im Reich nach einer Phase der Gefährdung zu Beginn des Jahrhunderts durch die Ottonen konsolidiert worden war und schließlich sogar zum Kaisertum gesteigert werden konnte und sich in Böhmen die anfangs noch sehr unübersichtlichen Herrschaftsverhältnisse zunehmend zugunsten der Přemysliden klärten. Natürlich haben in den Quellen wiederum Kriegszüge die deutlichsten Spuren hinterlassen ${ }^{47}: 929$ war Heinrich I. in Prag und stellte die Hoheit über das

40 Vgl. HARTMANN, Ludwig der Deutsche, S. 113.

41 Vgl. ebd. S. 113-119 und Eric J. GOLDBERG, Ludwig der Deutsche und Mähren. Eine Studie zu karolingischen Grenzkriegen im Osten, in: Wilfried Hartmann (Hg.), Ludwig der Deutsche und seine Zeit. Darmstadt 2004, S. 67-94, sowie Herwig WOLFRAM, Grenzen und Räume. Geschichte Österreichs vor seiner Entstehung. Wien 1995, S. 315-321.

42 Vgl. dazu und besonders zu der Problematik um Methodius HARTMANN, Ludwig der Deutsche, S. 209 ff.; WOLFRAM, Grenzen und Räume, S. 260-266, und Franz-Reiner ERKENS, Die ältesten Passauer Bischofsurkunden, in: ZBLG 46 (1983), S. 469-514, bes. S. 478 ff. und die dort in Anm. 54 angeführte Literatur, sowie Die Regesten der Bischöfe von Passau. Bd. 1: 731-1206, bearb. von Egon BOSHOF. München 1992, Nr. 146-148.

43 Zur Diskussion über die Lage des,Großmährischen Reiches` vgl. HARTMANN, Ludwig der Deutsche, S. 114 f., und Thomas WÜNSCH, Deutsche und Slawen im Mittelalter. Beziehungen zu Tschechen, Polen, Südslawen und Russen. München 2008, S. 37 f.

44 Vgl. den Brief des Passauer Erzbischofs Theotmar von 900, in: Die Fälschungen Pilgrims von Passau. Historisch-kritische Untersuchung und Edition nach dem Codex Gottwicensis 53a (rot), 56 (schwarz), bearb. und hg. von Franz-Reiner ERKENS. München 2011, S. 45, Nr. 8, und dazu ebd. S. 119-127.

45 Vgl. Egon BOSHOF, Die Passauer Mission, in: Franz-Reiner Erkens (Hg.), Königtum, Kirche und Mission im Südosten des Reiches. Ausgewählte Aufsätze von Egon Boshof. Festgabe zum 75. Geburtstag. Passau 2012, S. 25-31 [erstmals 1997], sowie DERS., Das ostfränkische Reich und die Slawenmission im 9. Jahrhundert, in: ebd. S. 33-60 [erstmals 1998], dagegen Dušan TŘEŠTÍK, Großmähren, Passau und die Ungarn um das Jahr 900. Zu den neuen Zweifeln an der Authorizität des Briefes der bayerischen Bischöfe an Papst Johann IX. aus dem Jahr 900, in: Byzantinoslavica 59 (1998), S. 137-160, bes. 141-150, und allg. ERKENS, Die Fälschungen Pilgrims von Passau, S. ${ }^{\star} 121 \mathrm{f}$.

46 Vgl. das Raffelstettener Zollweistum, hg. von Lorenz WEINRICH, Quellen zur deutschen Verfassungs-, Wirtschafts- und Sozialgeschichte bis 1250. Darmstadt 1977, S. 16 (Nr. 4 [5]: Sclavi vero, qui de Rugis vel de Boemanis mercandi causa exeunt, [...] und [8]: Si autem transire voluerint ad mercatum Marahorum, $[\ldots])$.

47 Die Regesten des Kaiserreichs unter Heinrich I. und Otto I. 919-973, neubearb. von Emil VON OTTENTHAL mit Ergänzungen von Hans H. KAMINSKY (= J. F. Böhmer, Regesta Imperii II. Sächsisches Haus 919-1024, 1. Abt.). Hildesheim 1967, Nr. 23e (929 Prag), 189a und 190a (950). 
Herzogtum wieder her; 950 zog Otto der Große kriegerisch durch das Land und brachte den Herzog und seinen Sohn erneut zur Unterwerfung.

Jetzt, nämlich in dem Bericht über den Prager Aufenthalt des Jahres 929, wird die Oberhoheit des ostfränkischen Herrschers über Böhmen auch erstmals richtig deutlich, während sie und ihre genaue Ausgestaltung für das 9. Jahrhundert nur vermutet werden kann wegen der spärlichen Quellen. Außerdem übten die Karolinger sie kaum ununterbrochen aus, war der böhmische Raum doch zeitweise den Mährern unterworfen. Erst 895 unterstellten sich angeblich alle böhmischen duces wieder dem fränkischen Herrscher ${ }^{48}$. Ob dieser wirklich eine wie auch immer geartete Hoheit in den folgenden Jahren und den ersten Jahrzehnten des 10. Jahrhunderts ausüben konnte, ist aber eher zweifelhaft. Erst seit 929 änderte sich das allmählich. Natürlich manifestierte sich diese Hoheit vorrangig in der böhmischen Tributpflicht ${ }^{49}$, in einer Zahlung, die sich nach Cosmas von Prag auf jährlich 500 Mark und 120 Rinder belief und angeblich schon von Karl dem Großen festgesetzt worden sein soll ${ }^{50}$. Doch intensivierte sich diese Oberhoheit offenbar im Lauf der Zeit - und dies nicht zuletzt, weil eine Monopolisierung der Herrschaft über den böhmischen Volksverband zugunsten der Přemysliden stattgefunden hatte.

Waren die böhmischen Herrschaftsverhältnisse zur Karolingerzeit noch amorph und unübersichtlich - vierzehn duces ließen sich 845 zusammen mit ihrem Gefolge taufen und repräsentierten dabei noch nicht einmal die Gesamtheit der Böhmen ${ }^{51}$, alle duces, also noch immer eine Vielzahl, unterstellten sich 895 Arnulf von Kärnten -, so gab es für die Ottonen in dem přemyslidischen Herzog einen eindeutigen Ansprechpartner, der in dem Maße, wie sich seine Herrschaft über die Böhmen festigte, auch die Oberhoheit des Reiches sicherte, solange er loyal war, und der bei Illoyalität als Gegner zu bekämpfen und zur Umkehr zu zwingen oder durch einen ergebeneren Gefolgsmann zu ersetzten war. Die Jahrzehnte nach der Jahrtausendwende bieten genügend Anschauungsmaterial

48 Vgl. die Annales Fuldenses sive Annales regni Francorum orientalis. Cont. Ratisbonensis a. 895, S. 126 (Mediante mense Iulio habitum est urbe Radasbona generale conventum; ibi de Sclavania omnes duces Boemanorum, quos Zwentibaldus dux a consortio et potestate Baioaricae gentis per vim dudum divellendo detraxerat, quorum primores erant Spitignewo, Witiza, ad regem venientes et honorifice ab eo recepti per manus, prout mos est, regiae potestati reconciliatos se subdiderunt.), und dazu HOFFMANN, Böhmen und das deutsche Reich im hohen Mittelalter, S. $18 \mathrm{ff}$.

49 Vgl. Widukindi monachi Corbeienses Rerum gestarum Saxonicarum libri III, in Verbindung mit H.E. Lohmann neu bearb. von Paul HIRSCH - Hans-Eberhard LOHMANN (MGH Scriptores rerum Germanicarum in usum scholarum separatim editi. Bd. 60). Hannover 1935, S. 50 f. (I 35: [...] Pragam adiit cum omni exercitu, Boemiorum urbem, regemque eius in deditionem accepit; [...]. Igitur rex Boemias tributarias faciens [...]). Die Zahlungspflicht endete offenkundig erst um 1200: Vgl. Die Urkunden Friedrichs II. 1212-1217, bearb. von Walter KOCH unter Mitwirkung von Klaus HÖFLINGER Joachim SPIEGEL - Christian FRIEDL (MGH Die Urkunden der deutschen Könige und Kaiser. Bd. 14. Teil. 2). Hannover 2007, Nr. 171 (Basel, 1212 Sept. 26: Friedrich bestätigt dem König Ottokar von Böhmen nach dem Vorbild seines Vorgängers und Oheims Philipp von Schwaben [vgl. Die Urkunden Philipps von Schwaben, bearb. von Andrea RZIHACEK - Renate SPREITZER unter Mitwirkung von Brigitte MERTA - Christine OTTNER-DIESENBERGER (Die Urkunden der deutschen Könige und Kaiser. Bd. 12). Wiesbaden 2014, Nr. 19 (wohl Mainz, 1198 Sept. 8)] die Königswürde absque omni pecunie exactione et consueta curie nostra iusticia).

50 Vgl. Anm. 32 sowie Georg WAITZ, Deutsche Verfassungsgeschichte. Bd. 8: Die deutsche Reichsverfassung von der Mitte des neunten bis zur Mitte des zwölften Jahrhunderts. Kiel 1878, S. 373 (und 372 mit Anm. 4), und HOFFMANN, Böhmen und das deutsche Reich im hohen Mittelalter, S. 6, 9, 24.

51 Vgl. Anm. 38 . 
für dieses politische Spiel ${ }^{52}$. Daneben muss es, auch wenn die Quellen kaum etwas darüber berichten, zu stärkeren wirtschaftlichen Kontakten gekommen sein. Erwähnt das Zollweistum von Raffelstetten zu Beginn des 10. Jahrhunderts nur ganz allgemein böhmische Kaufleute ${ }^{53}$, so ist davon auszugehen, dass der Handelsverkehr von Linz aus über den Haselgraben verlief ${ }^{54} .1010$ ist dann, wenn auch nur indirekt, erstmals jener Steig zwischen Passau und Prachatitz belegt, der hauptsächlich, aber nicht ausschließlich dem Salzhandel diente und zu Beginn des 16. Jahrhunderts als „golden“ bezeichnet worden ist ${ }^{55}$. Der 1010 von Heinrich II. an das Passauer Kloster Niedernburg übertragene böhmische Zoll ${ }^{56}$ kündet dabei zugleich von recht regen Handelsbeziehungen.

Am wichtigsten für die Verflechtung Böhmens mit dem Reich ist aber zweifellos die kirchliche Entwicklung gewesen. Wenn über die Missionstätigkeit im Einzelnen auch wenig bekannt ist, so war sie doch sehr erfolgreich und schuf dauerhafte Verbindungen zwischen der Reichskirche und Böhmen. Und gerade auf kirchlichem Gebiet zeigt sich am deutlichsten das Ausmaß, in dem Böhmen in den Reichsverband einbezogen war, denn es waren die ottonischen Herrscher, Otto I. beginnend, Otto II. vollendend, die das Bistum Prag und ein Bistum für Mähren 973 auf die Wege brachten im Verein mit dem böhmischen Herzog und dem Papst und die vor allem dafür sorgten, dass die neuen Diözesen der Mainzer Kirchenprovinz und damit dem Kirchenverbund des Reiches angegliedert wurden ${ }^{57}$. Fortan wurden die Bischöfe Böhmens und Mährens bis ins

$52 \mathrm{Zu}$ dem oft blutigen, von Gewalt und Hinterlist bestimmten Geschehen vgl. die Darstellung von BACHMANN, Geschichte Böhmens 1, S. 182-201, bes. 186, 189 f., 192 und 200 ff., sowie Siegfried HIRSCH, Jahrbücher des Deutschen Reiches unter Heinrich II. Bd. 1. Berlin 1862, S. 231 f., 251 f., 317 ff.; Bd. 2, vollendet von Hermann Pabst. Berlin 1864, S. 337 ff.; Harry BRESSLAU, Jahrbücher des Deutschen Reichs unter Konrad II. Bd. 2: 1032-1039. Leipzig 1884, S. 84, 98, 102, 120 ff., 133, und LÜBKE, Das östliche Europa, S. 222-225 und 253. Die Eingriffe Heinrichs II. und Konrads II. zeigen sich bei dem Wechsel von dem vertriebenen Boleslav III. zu dem von Heinrich II. anerkannten Vladivoj, von diesem - nach einem kurzen Zwischenspiel des zurückgekehrten Boleslavs III. - zu dem Polen Bolesław Chrobry, der über seine Mutter ein Enkel Boleslavs I. war, aber von Heinrich II. vertrieben und durch Jaromír, den Bruder Boleslavs III., ausgetauscht wurde, bis Heinrich II. an dessen Stelle einen weiteren Bruder von Boleslav III., Oldřich, setzte, der dann seinerseits von Konrad II. abgesetzt und durch den alten Jaromír ersetzt wurde, der sich schließlich aber gemäß kaiserlichen Willens die Herrschaft mit seinem Bruder Oldřich teilen musste und von diesem geblendet wurde und dessen Sohn Břetislav nach des Vaters Tode das Herzogtum von Konrad II. übertragen erhielt.

53 Vgl. Anm. 46.

54 Vgl. Paul PRAXL, Das Alter des Goldenen Steiges, in: Ostbairische Grenzmarken 3 (1959), S. 112-123, bes. 114, und DERS., Der Goldene Steig. Salzwege von Passau nach Böhmen, in: Manfred Treml u. a. (Hgg.), Salz Macht Geschichte. Aufsätze. Regensburg 1995, S. 332-340, bes. 332.

55 Vgl. Franz-Reiner ERKENS, Heinrich II., Niedernburg und der böhmische Zoll, in: Ders. (Hg.), 1000 Jahre Goldener Steig. Passau 2011, S. 1-12.

56 Die Urkunden Heinrichs II. und Arduins, hg. von Harry BRESSLAU u. a. (MGH Die Urkunden der deutschen Könige und Kaiser. Bd. 3). Berlin 1900-1903, Nr. 214 (1010 April 19: cum toto tamen Boemiensi theloneo).

57 Vgl. Peter HILSCH, Der Bischof von Prag und das Reich in sächsischer Zeit, in: DA 28 (1972), S. 1-41; Ernst-Dieter HEHL, Die Mainzer Kirche in ottonisch-salischer Zeit (911-1122), in: Friedhelm Jürgensmeier (Hg.), Handbuch der Mainzer Kirchengeschichte. Bd. 1/1: Christliche Antike und Mittelalter. Würzburg 2000, S. 195-280, bes. 225 f., sowie neuestens Tina BODE, König und Bischof in ottonischer Zeit. Herrschaftspraxis - Handlungsspielräume - Interaktionen. Husum 2015, S. 527-537. Zu der hier nicht zu verfolgenden Frage, warum die neuen Bistümer der Mainzer und nicht der bayerisch-salzburgischen oder der neuen magdeburgischen Kirchenprovinz angegliedert worden sind, vgl. Heinrich BÜTTNER, Erzbischof Willigis von Mainz und das Papsttum bei der Bistumserrichtung in Böhmen und Mähren im 10. Jh., in: Rhein. Vierteljahrsblätter 30 (1965), S. 1-22, bes. 9 f.; BOSHOF, Mainz, Böhmen und das Reich, S. 24, und BODE (wie oben), S. 534 ff. 
13. Jahrhundert hinein vom deutsch-römischen König investiert ${ }^{58}$ und bis ins 14. Jahrhundert hinein vom Mainzer Metropoliten geweiht (in den ersten Jahrzehnten allerdings weder in Prag noch in Mainz, sondern, soweit überliefert, an anderen Orten: Thietmar vielleicht im Elsass, Adalbert in Verona, Ekkehard in Merseburg, Izzo in Bamberg ${ }^{59}$ ). Natürlich nahm der Bischof Böhmens, freilich nicht häufig oder nur selten belegt, auch an Synoden im Reich teil: 976 mit einer gewissen Wahrscheinlichkeit zusammen mit dem mährischen Bischof an einer Mainzer Provinzialsynode, 996 an der Krönungssynode Ottos III. in Rom (wo Adalbert von Prag damals ohnehin weilte und von dem Kaiser in seinem klösterlichen Rückzugsort auf dem Aventin aufgesucht worden ist), 1024 an der Reformsynode von Höchst (oder zumindest an einem Bischofstreffen), 1046 an der Synode von Pavia und 1049 an der Mainzer Reformsynode Leos IX ${ }^{60}$. Es waren mithin meist Versammlungen, an denen auch der (künftige) Kaiser mitwirkte (996, 1046, 1049) und manchmal auch der Papst (996, 1049), wobei der Prager Bischof 996 nicht eigens nach Rom zur Kaiserkrönung und Synode Ottos III. anreiste, sondern seine Anwesenheit anderen, besonderen Umständen zu verdanken war $^{61}$. Auf einer reinen Provinzialsynode sind die Prager Oberhirten hingegen, wenn das späte, davon kündende Zeugnis zutrifft, nur einmal belegt: nämlich im April 976, also als das Prager und das mährische Bistum gerade erst eingerichtet worden waren und die beiden neuen Bischöfe sich wohl auch deshalb in der Umgebung ihres Metropoliten aufhielten.

Das Reich und seine Herrscher waren mithin der entscheidende Bezugspunkt der böhmisch-mährischen Kirche. Der Papst hingegen, dessen Autorität grundsätzlich anerkannt war und der bei der Einrichtung der Bistümer nicht übergangen werden konnte, war um die erste Jahrtausendwende doch eine eher ferne Größe: in der Theorie verehrt als Oberhaupt, in der Praxis selten aufgesucht. Konkrete Beziehungen zwischen Böhmen

58 Vgl. HILSCH, Der Bischof von Prag, S. 4 f.

59 Regesten zur Geschichte der Mainzer Erzbischöfe von Bonifatius bis Heinrich II. 742?-1288. Bd. 1: Von Bonifatius bis Arnold von Selehofen 742?-1160, bearb. und hg. von Cornelius WILL. Innsbruck 1877, S. 119 Nr. 12 (975 oder 976: Weihe Thietmars durch Erzbischof Willigis im elsässischen Brumath gemäß später und daher nicht unbedingt zuverlässiger Nachricht; vgl. HILSCH, Der Bischof von Prag, S. 14); S. 122 Nr. 36 (983 Juni 29: Weihe Adalberts durch Erzbischof Willigis in Verona); S. 132 Nr. 127 (998 Juli 7: Weihe Thiddags durch Erzbischof Willigis an unbekanntem Ort); S. 147 Nr. 19 (1017 Okt. 6: Weihe Ekkehards durch Erzbischof Erkenbald in Merseburg); S. 153 Nr. 17 (1023 Dez. 29: Weihe Izzos durch Erzbischof Aribo in Bamberg); S. 165 Nr. 2 (1031 Juni 29: Weihe des Severus durch Erzbischof Bardo am Tag von dessen Bischofsweihe an unbekanntem Ort; vgl. Harry BRESSLAU, Jahrbücher des Deutschen Reichs unter Konrad II. Bd. 1: 1024-1031. Leipzig 1879, S. 322, Anm. 3). Allein die angebliche Weihe eines Bruders des böhmischen Herzogs, von der Cosmas von Prag (Die Chronik der Böhmen, S. 55) mehr als hundert Jahre nach dem vermeintlichen Ereignis berichtet, die aber wohl nicht nur nicht stattgefunden hat, weil der Consecrandus bei der Feier plötzlich starb, sondern einfach deshalb, weil sie wohl niemals in Aussicht genommen worden ist (vgl. HILSCH, Der Bischof von Prag, S. 30), wird in Mainz lokalisiert: Regesten (wie oben), S. 131 Nr. 121.

60 Vgl. WOLTER, Die Synoden im Reichsgebiet und in Reichsitalien, S. 112 ff., bes. 114 (Mainzer Provinzialsynode von 976; Anwesenheit belegt durch eine gefälschte Urkunde, deren historische Nachrichten aber als korrekt gelten: Urkundenbuch des Stifts St. Peter und Alexander zu Aschaffenburg. Bd. 1: 861-1325, bearb. von Matthias THIEL, Aschaffenburg 1986, S. 27 Nr. 8 [Mainz 976 April 28], dazu ebd. S. 28 f.; Germania pontificia. Bd. 4: Provincia Maguntinensis. Teil 4: S. Bonifatius, archidioecesis Maguntinensis, abbatial Fuldensis, hg. von Hermann JAKOBS, Göttingen 1978, S. 80 Nr. 79 [Mainz, 976 April 28], und HEHL, Die Mainzer Kirche, S. 225 f.); S. 144-151, bes. 146 ff. (Krönungssynode Ottos III.), S. 306-312, bes. 309 ff. (Synode von Höchster, vgl. zu dem Schreiben der Bischöfe an den Papst: Germania pontificia 4/4 [wie oben] S. 87 Nr. 104), S. 374-379, bes. 375 (Synode von Pavia), S. 409-417, bes. 410 (Synode von Mainz).

61 Vgl. Anm. 63. 
und der römischen Kirche intensivierten sich nach Ausweis der erhaltenen Urkunden erst im Laufe des 11. Jahrhunderts ${ }^{62}$; davor häufen sie sich, letztlich abhängend von besonderen Situationen, nur unter dem zweiten Prager Bischof Adalbert aus der Familie der Slavnikiden ${ }^{63}$, bei dessen Amtsantritt das mährische Bistum mit dem Prager vereint worden ${ }^{64}$ und der zweimal, 988 bis 992 und 995/996, vor den Problemen in Prag nach Rom ausgewichen ist, die Bekanntschaft Ottos III. machte, schließlich am 23. April 997 als Glaubensbote den Märtyrertod bei den Prußen fand, rasch in den Himmel der Heiligen aufstieg und nun mehr noch als schon zu Lebzeiten von dem jungen Kaiser verehrt wurde. Das letztlich vergebliche Bemühen, Adalbert zur Rückkehr nach Prag (wo er freilich nicht allzu beliebt war ${ }^{65}$ ) und zur Erfüllung seiner Pflichten als Bischof zu bewegen, brachte immerhin einige Boten und Briefe (vom Papst, vom böhmischen Herzog, vom Mainzer Erzbischof ${ }^{66}$ ) auf die Wege. Außer Adalbert jedoch, der aber eben nicht in seiner Funktion als geistlicher Oberhirte am Tiber weilte, dürfte kein weiterer böhmischer Bischof der damaligen Zeit jemals einen Papst zu Gesicht bekommen haben, auch nicht 1020, als Benedikt VIII. in Bamberg und Fulda weilte ${ }^{67}$.

Im Gegensatz dazu waren die frühen Prager Bischöfe, die von Herkunft oder Erziehung alle einen sächsischen Hintergrund aufweisen ${ }^{68}$, über deren geistliches Wirken ansonsten jedoch recht wenig bekannt ist, wiederholt in der Umgebung des Kaisers oder im Binnenreich anzutreffen: bei den bereits erwähnten Synoden und bei der Investitur durch den König und Kaiser (auch wenn nicht jede ihren Niederschlag in den Quellen gefunden hat). Thiddag schließlich, der mit Herzog Boleslav III. in Konflikt geriet und sich daher wiederholt in den Schutz des Markgrafen Ekkehard von Meißen begeben musste ${ }^{69}$, hat 1004 sogar Heinrich II. in Prag begrüßen können (gemeinsam mit dem neuen, von dem König gegen Bolesław Chrobry durchgesetzten Herzog Jaromír) ${ }^{70}$. Auch später noch erwies sich dieses königlich-bischöfliche Beziehungssystem als recht

62 Vgl. Bohemia-Moravia pontificia vel etiam Germania ponficia. Bd. 5, Teil 3: Provincia Maguntinensis. Teil 7: Dioeceses Pragensis et Olomocensis, hg. von Waldemar KÖNIGHAUS. Göttingen 2011, S. 43 Nr. 21 (1072/1073); S. 80 Nr. 24 (1061-1067 Dez. 9?), S. 83 Nr. 39 (1074 Ian. 31).

63 Vgl. dazu und zum folgenden HEHL, Die Mainzer Kirche, S. 232 und 233 ff.; HILSCH, Der Bischof von Prag, S. 16-29.

64 Vgl. Bohemia-Moravia pontificia (wie oben), S. 74 Nr. ${ }^{\star} 15$ (983 Anfang).

65 Vgl. ebd. S. 74 Nr. ${ }^{\star} 6$ (988/989) sowie HILSCH, Der Bischof von Prag, S. 19 und 28.

66 Vgl. Bohemia-Moravia pontificia (wie Anm. 62), S. 75 Nr. ${ }^{\star} 7$ ([992]: Willigis an Papst Johannes XV.); S. 76 Nr. ${ }^{\star} 13$ ([996 Mai-Juni]: Willigis an Papst Gregor V.) und Nr. ${ }^{\star} 14$ (Rom 996 Anfang Juni: [wohl auch schriftlich erteilte] Missionserlaubnis Gregors V. für Adalbert für den Fall, dass Adalbert in Prag nicht wohl aufgenommen wird); Regesten zur Geschichte der Mainzer Erzbischöfe (wie Anm. 59), S. 129 Nr. ${ }^{\star} 105$ (994: Willigis an Adalbert); S. 130 Nr. ${ }^{\star} 113$ (995: Herzog Boleslav an Willigis), vgl. auch ebd. S. 131 Nr. ${ }^{\star} 118$ (Rom 996 Mai) und Bohemia-Moravia pontificia (wie oben), S. 76 Nr. ${ }^{\star} 12$ (Rom 996 Mai 25).

67 Unter den bei diesem Besuch in der Umgebung des Papstes bezeugten Großen wird Ekkehard von Prag nicht genannt. Vgl. Die Regesten des Kaiserreiches unter Heinrich II. 1002-1024, neubearb. von Theodor GRAFF (= J. F. Böhmer, Regesta Imperii II. Sächsisches Haus: 919-1024, 4. Abt.). Wien 1971, Nr. 1962a (Bamberg, 1020 April 14-17) - 1971 (Kaufungen, 1020 Mai 22) und bes. Nr. 1968.

68 Vgl. HILSCH, Der Bischof von Prag, S. 13 f. (Thietmar war ein sächsischer Mönch vielleicht aus Corvey); S. 17 (der Slavnikide Adalbert ist an der Magdeburger Domschule ausgebildet worden); S. 31 (Thiddag war ein Mönch aus Corvey); S. 35 f. (Ekkehard war Abt von Nienburg) und S. 37 (Izzos Herkunft ist unbekannt, doch stammte er wohl nicht aus Böhmen); zu Thietmar und Adalbert vgl. jetzt auch BODE, König und Bischof, S. 212-239.

69 Vgl. Thietmari Chronicon, S. 468/469 (VII 56).

70 Vgl. ebd. S. 290/291 (VI 12). 
stabil. Als Heinrich III. 1041 in militärischem Konflikt mit dem Herzog Břetislav lag, lief Bischof Severus, der erste Prager Oberhirte, der vom Herzog und nicht vom Kaiser ausgesucht worden war $^{71}$ und der eine Zeit lang an der Seite Břetislavs ausgeharrt hatte, zusammen mit weiteren Großen heimlich zu dem Salier über und wurde - natürlich in Gnade aufgenommen ${ }^{72}$. Von 1077 bis 1084 stand schließlich Jaromír-Gebhard, der Bruder des 1085 zum König erhobenen Herzogs Vratislav und seit 1068 Bischof von Prag, der (sog. deutschen) Kanzlei Heinrichs IV. vor ${ }^{73}$. In diesem Doppelverhältnis des salischen Herrschers zum böhmischen Herzog und Bischof von Prag, der, sieht man von dem Sonderfall des gegen Ende des 9. Jahrhunderts von seinem mährischen Bischofsitz vertriebenen Wiching $\mathrm{ab}^{74}$, als erster Bischof des Reichs zum Kanzler ernannt wurde und nicht das Kanzleramt als Sprungbrett für eine spätere Bischofskarriere brauchte, in dieser Duplizität der přemyslidischen Bindung an das salische Königtum spiegelt sich natürlich Heinrichs IV. gutes Verhältnis zur böhmischen Herrscherdynastie, aber auch die fortgeschrittene Integration Böhmens in den Reichsverband wider - auch wenn sich, Ironie der Geschichte, die beiden Brüder laut Cosmas von Prag nicht besonders gut verstanden haben $^{75}$. Allerdings brachten die Spannungen zwischen den Brüdern auch den Vorrang des Kaisers vor dem Herzog (und König) zum Ausdruck, wollte der Bischof doch allein dem Kaiser, der ihn ja in sein Amt investiert und ihm dabei das episcopium übergeben hatte, zu Diensten sein ${ }^{76}$.

Die sich intensivierende Integration Böhmens in das Reich, die in national oder sogar nationalistisch bewegter Zeit heftig umstritten war und dabei voller Leidenschaft diskutiert werden konnte, lässt sich auch ablesen an der Entwicklung des Hoheitsverhältnisses zwischen König und Herzog. Kern der karolingisch-ottonischen Oberhoheit ist zweifellos die böhmische Tributpflicht gewesen, von der aber nicht sicher feststeht, seit wann es sie gab und ob es sie dauerhaft gab. Nicht jede in den Quellen erwähnte Zahlung muss ihren Grund in dieser Pflicht gehabt haben; und ununterbrochen wird sie, so es sie gab, im 9. und frühen 10. Jahrhundert kaum bestanden haben, zumindest hatten die fränkischen Herrscher über lange Zeit wenig Möglichkeit, sie wirkungsvoll einzufordern. Eine Kontinuität der Tributzahlungen konnte erst seit 929 einsetzen, doch flossen die Tribute auch jetzt noch nicht ungestört und ununterbrochen, denn Herzog Boleslav, der seinen Bruder und Vorgänger beseitigt hatte und dann eine beachtliche Aufbauleistung vollbrachte ${ }^{77}$, versuchte ganz offenkundig, sich der Zahlungspflicht zu entziehen. Erst

${ }^{71}$ Vgl. HILSCH, Der Bischof von Prag, S. 37.

72 Annales Altahenses maiores, hg. von Edmund VON OEFELE (MGH Scriptores rerum Germanicarum in usum scholarum separatim editi. Bd. 4). Hannover 1891, S. 27 (a. 1041).

73 Vgl. Die Urkunden Heinrichs IV. Teil 3, bearb. von Alfred GAWLIK (MGH Die Urkunden der deutschen Könige und Kaiser. Bd. 6), S. XXXVIII-XLI; vgl. ebd. S. 389 (Nr. 295: 1077 Juni 11) und S. 492 (Nr. 369: 1084 Okt. 4).

74 Vgl. ERKENS, Die ältesten Passauer Bischofsurkunden, S. 478-482 und hier vor allem 480.

75 Die Chronik der Böhmen, S. 145 f. (II 41). Vgl. auch BOSHOF, Mainz, Böhmen und das Reich, S. 29-34.

76 Die Chronik der Böhmen, S. 146: [... ] soli imperatori suum profitetur servicium, a quo acceperat episcopium.

77 Vgl. Jiř́ SLÁMA, Der böhmische Fürst Boleslav II., in: Petr Sommer (Hg.), Boleslav II. Der tschechische Staat um das Jahr 1000. Praha 2001, S. 15-42, bes. 24-28. Zur böhmischen Tributpflicht und ihrem zunächst eher formalen Charakter vgl. LÜBKE, Das östliche Europa, S. 152. 
950 scheint Otto der Große diese dauerhaft durchgesetzt zu haben. Von nun an dürften Zahlungen bis 1198, bis zur Erhebung Böhmens zum Königreich erfolgt sein.

Aber bei Tributzahlungen allein blieb es nicht. Auch militärische Dienste waren zu leisten. Schon 955 erfochten böhmische Truppen vor den Toren von Augsburg den epochalen Sieg über die Ungarn mit ${ }^{78}$. Und schließlich griffen die Beherrscher des Reiches in strittigen Fällen bei der Regelung der Nachfolge im Herzogtum ein, erhoben 1085 und 1158 sogar zwei Herzöge zu Königen auf Lebenszeit und 1198/1212 das Herzogtum zum Königreich ${ }^{79}$. Ihre Hoheit über Böhmen ist mithin unverkennbar und sie ist, außer vielleicht um 1040, als möglicherweise ein gescheiterter Versuch unternommen worden ist, Prag zum Sitz eines Erzbischofs zu machen und gegenüber Polen eine eigenständige Politik betrieben wurde ${ }^{80}$, nicht mehr prinzipiell in Frage gestellt worden. Bezeichnungen für Art und Begründung dieses Herrschaftsverhältnis, das seit dem späteren 12. Jahrhundert zweifellos als Lehnsverhältnis verstanden worden ist ${ }^{81}$, finden sich aus dem 9., 10. und 11. Jahrhundert lediglich in nichtböhmischen Quellen und sind schwer zu deuten, seitdem die traditionellen Vorstellungen über die Entstehung des Lehnswesens im 8. Jahrhundert und die Entwicklung bis in die Stauferzeit hinfällig geworden sind $^{82}$. Vieles ist durch die Destruktion des herkömmlichen Erklärungsmodells unklar

78 Widukindi monachi Corbeienses Rerum gestarum Saxonicarum, S. 125 (III 46). Weitere Beispiele ließen sich anführen: 992 etwa unterstützte Boleslav II. das Unternehmen gegen die Elbslawen: Vgl. SLÁMA, Der böhmische Fürst Boleslav II., S. 35 f., und LÜBKE, Das östliche Europa, S. 155.

79 Vgl. Anm. 52 (und zusätzlich HOFFMANN, Böhmen und das deutsche Reich im hohen Mittelalter, S. 26, 32 und 34 f., sowie Martin WIHODA, Die Sizilischen Goldenen Bullen von 1212. Kaiser Friedrichs II. Privilegien für die Přemysliden im Erinnerungsdiskurs. Wien/Köln/Weimar 2012) und Anm. 30 (Königserhebungen). Zu der Königserhebung von 1158 (die ursprünglich offenbar nicht auf die Person des neuen Königs beschränkt sein sollte, es de facto aber war) vgl. Anm. 30 sowie Jiří KEJŘ, Böhmen und das Reich unter Friedrich I., in: Alfred Haverkamp (Hg.), Friedrich Barbarossa. Handlungsspielräume und Wirkungsweisen des staufischen Kaisers. Sigmaringen 1992, S. 240-289, bes. 251-257; zu der Königserhebung von 1085 vgl. Zdeněk FIALA, Die Urkunde Friedrichs I. für den böhmischen Fürsten Vladislav II. vom 18. I. 1158 und das „Privilegium minus“ für Österreich, in: MIÖG 78 (1970), S. 167-192, bes. 171, der sich angesichts der spärlichen Quellen nicht völlig zu Unrecht zurückhaltend äußert über eine 1085 lediglich ad personam vollzogene Königserhebung. De facto ist es aber so gewesen, und man darf wohl annehmen, dass eine grundsätzliche Erhebung der Přemysliden zu Königen einen Anspruch geschaffen hätte, der in den folgenden Jahrzehnten eingefordert worden wäre, was aber nicht geschah.

80 Vgl. Bohemia-Moravia Pontificia 5/3,7, S. 77 f. Nr. ${ }^{\star} 16-{ }^{\star} 19$ sowie die Die Chronik der Böhmen (II 6 und 7) S. 91 und 92 f.; Die Reichschronik des Annalista Saxo, hg. von Klaus NASS (Scriptores Bd. 37). Hannover 2006, S. 385 (a. 1042; zu der erst rund hundert Jahre nach dem Ereignis aufgezeichneten Nachricht und ihrer vermuteten Quelle, den verlorenen Annales Hildesheimenses maiores [vgl. Annales Magdeburgenses, hg. von Georg Heinrich PERTZ u. a., in: MGH Scriptores (in Folio). Bd. 16: Historiae aevi Suevici. Hannover 1859, S. 105-196, hier 17220-26 (a. 1042)], vgl. DERS., Die Reichschronik des Annalista Saxo und die Geschichtsschreibung im 12. Jahrhundert. Hannover 1996, S. 345 ff. und 86-92 und hier bes. 90), und dazu Egon BOSHOF, Das Reich und Ungarn in der Zeit der Salier, in: Erkens (Hg.), Königtum, Kirche und Mission, S. 113-139 [erstmals 1986], bes. 119; DERS., Mainz, Böhmen und das Reich, S. 28, und LÜBKE, Das östliche Europa, S. $253 \mathrm{ff}$.

81 Vgl. HOFFMANN, Böhmen und das deutsche Reich im hohen Mittelalter, S. 34 f. mit Anm. 125.

82 Vgl. Steffen PATZOLD, Das Lehnswesen. München 2012, bes. Kap 2 und 3; Jürgen DENDORFER Roman DEUTINGER (Hgg.), Das Lehnswesen im Hochmittelalter. Forschungskonstrukte - Quellenbefunde - Deutungsrelevanz. Ostfildern 2010; Susan REYNOLDS, Fiefs and Vassals. The Medieval Evidence Reinterpreted. Oxford 1994 (und dazu Karl Friedrich KRIEGER, in: HZ 264 [1997], S. 174-179; Johannes FRIED, in: German Historical Institute London. Bulletin 19/1 [1997], S. 28-41; Susan REYNOLDS, ebd. 19/2 [1997], S. 30-40; Klaus-Peter MATSCHKE, Feudalismus ade? Ein Byzantinist liest S. Reynolds, in: Rechtshistorisches Journal 14 [1995], S. 87-92; Otto Gerhard OEXLE, Die Abschaffung des Feudalismus ist gescheitert, in: Frankfurter Allgemeine Zeitung Nr. 116 vom 19. Mai 1995). 
und unsicher geworden; sicher ist letztlich nur, dass Begriffe, die bislang uneingeschränkt dem Lehnswesen zugeordnet wurden, diese Eindeutigkeit verloren haben. In den Quellen ist für 895 und 950 von Unterwerfung die Rede ${ }^{83}$, für 929 und 977 von deditio des Herzogs und für 950 von ditio des Königs ${ }^{84} .1003$ heißt es, der Herzog solle dem König dienen (servire) ${ }^{85}$, und 1041 versprach der rebellische Břetislav bei seiner Unterwerfung dem Salier Heinrich III., der vom Niederaltaicher Annalisten ausdrücklich als senior des Böhmen bezeichnet wird ${ }^{86}$, die Treue, die ein miles seinem senior schuldet ${ }^{87}$. Offenkundig ist die Wortwahl des 9. und 10. Jahrhunderts wenig spezifisch und belegt letztlich nur die Unterwerfung, die immer mit einer Huldigung verbunden gewesen sein dürfte. Auch der im frühen 11. Jahrhundert geforderte Dienst muss nicht zwingend der eines Lehnsmanns gewesen sein und das Bedeutungsspektrum von miles ist ohnehin weit und groß. Allerdings wurde schon 1002 bei der Anerkennung Vladivojs als Herzog davon gesprochen, der Herzog habe sich Heinrich II. zum Herrn erwählt (in domnum elegit) und alles, was er erbat, als beneficium erhalten ${ }^{88}$. Doch ist dieser Begriff bekanntlich noch 1157 mehrdeutig gewesen ${ }^{89}$. Trotzdem lässt sich der Eindruck nicht völlig von der Hand weisen, dass die Bindung zwischen den böhmischen Herzögen und den ottonischen und salischen Herrschern im 11. Jahrhundert zunehmend einen vasallitischen Charakter ${ }^{90}$ annahm.

83 Vgl. Anm. 48 und Les Annales de Flodoard, hg. von Philippe LAUER. Paris 1905, S. 127 f. (Otto rex [...] regem ipsorum [= Herzog Boleslav I.] in subjectionem recipit). Zur subiectio als Huldigung vgl. Matthias BECHER, Die subiectio principum. Zum Charakter der Huldigung im Franken- und Ostfrankenreich bis zum Beginn des 11. Jahrhunderts, in: Airlie - Pohl - Reimitz (Hgg.), Staat im frühen Mittelalter, S. 163-178.

84 Vgl. Anm. 49 sowie Annales Altahenses maiores (a. 977), S. 13 und Continuatio Reginonis, hg. von Friedrich KURZE, in: Reginonis abbatis Prumiensis Chronicon cum continuatione Treverensi (MGH Scriptores rerum Germanicarum in usum scholarum separatim editi. Bd. 50). Hannover 1890, S. 154-179, hier 164 (a. 950: Boemorum princeps Bolizlao regi rebellat; quem rex [...] suae [...] per omnia dicioni subdebat.). Zur deditio vgl. Gerd ALTHOFF, Das Privileg der ,Deditio. Formen gütlicher Konfliktbeendigung in der mittelalterlichen Adelsgesellschaft, in: DERS., Spielregeln der Politik im Mittelalter, S. 99-125 [erstmals 1997].

85 Thietmari Chronicon, S. 255 und 257 (V 31: Heinrich II. sendet Boten an den polnischen Fürsten Bolesław Chrobry, der Prag eingenommen hat, und erklärt diesem: si terram nuper a se occupatam de sua gracia, ut ius antiquum poscit, retinere sibique in omnibus fideliter vellet servire, se eius voluntati in hiis assentire, $[\ldots])$.

86 Annales Altahenses maiores (a. 1041), S. 25.

87 Ebd. S. 27 ([...], iusiurandum regi fecit, ut tam fidelis illi maneret, quam miles seniori esse deberet, [...]).

88 Thietmari Chronicon S. 249 (V 23: Iste [= Wladiwoj] [...] ad regem Ratispone adhuc commorantem proficiscens, cum humili subiectione et fideli promissione hunc in domnum elegit et, que postulavit ab eo, in beneficium acquisivit). Vgl. dazu BECHER, Die subiectio principum, S. 177.

$89 \mathrm{Vgl}$. Walter HEINEMEYER, „beneficium - non feudum sed bonum factum“. der Streit auf dem Reichstag zu Besançon 1157, in: Archiv für Diplomatik 15 (1969), S. 155-236, bes. 214 f. mit Anm. 192-194; Roman DEUTINGER, Kaiser und Papst: Friedrich I. und Hadrian IV., in: Ders. - Dendorfer (Hgg.), Das Lehnswesen, S. 329-345, bes. 338-342 und hier vor allem 339; Brigitte KASTEN, Beneficium zwischen Landleihe und Lehen - eine alte Frage, neu gestellt, in: Dieter R. Bauer u. a. (Hgg.), Mönchtum - Kirche - Herrschaft. 750-1000. Sigmaringen 1998, S. 243-260.

90 Vgl. HOFFMANN, Böhmen und das deutsche Reich im hohen Mittelalter, S. 29-32, bes. 31, der zwar sehr vorsichtig ist bei der Charakterisierung des ottonisch-böhmischen Verhältnisses als Vasallität, diese aber entsprechend den Vorstellungen seiner Zeit seit 1002 als gegeben ansieht. Vgl. dazu auch WÜNSCH, Deutsche und Slawen, S. 38-41 (wo das umstrittene Problem der Zugehörigkeit Böhmens zum Reich behandelt wird) und hier bes. 40 . Zu den Schwierigkeiten, das rechtliche Verhältnis des Böhmenherzogs zum Beherrscher des Reiches terminologisch angemessen zu erfassen, vgl. auch KEJǨ, Böhmen und das Reich unter Friedrich I., S. 243 f., 248, 288 f., und FIALA, Die Urkunde Friedrichs I., S. $173 \mathrm{ff}$. 
Unabhängig davon und von der Terminologie, die man wählt, um die Integration Böhmens in den Reichsverband zu charakterisieren, dürfte in der politischen Realität entscheidend gewesen sein, dass der Beherrscher des Reiches es als sein Recht ansah, über das Herzogtum Böhmen zu verfügen ${ }^{91}$ und die böhmischen Herzöge sich diesem Anspruch nicht entziehen konnten. Die Huldigung, die von ihnen geleistet werden musste, verlieh diesem Umstand herrschaftlichen und rechtlichen Ausdruck. Ansonsten jedoch konnten die böhmischen Herzöge offenbar weitgehend unabhängig schalten und walten, übten die Könige und Kaiser, die in Böhmen über kein Reichsgut verfügten und das Land auch nicht bei ihrem Umritt durch das Reich aufsuchten ${ }^{92}$, keine unmittelbare Herrschaft aus, begnügten sich also mit der Anerkennung ihrer Autorität und dachten dabei offenbar niemals daran oder, was wahrscheinlicher ist, besaßen - wie offenkündig auch in Sachsen ${ }^{93}$ - keine Möglichkeit dazu, bei der Vergabe des Herzogtums von der herrschenden Dynastie der abzugehen.

Die Hoheit der Ottonen und Salier über Böhmen, basierend auf Autorität, militärischem Gewicht, kirchlicher Verstrebung und - wie noch auszuführen ist - gegenseitigem Nutzen, entsprach mithin den Möglichkeiten des lockeren Herrschaftsgefüges im Reich um die erste Jahrtausendwende. Und dieses lockere Reichsgefüge, diese unverdichtete Staatlichkeit, bei der die Alterität im Vergleich zu den neuzeitlichen Verhältnissen $\mathrm{zu}$ beachten ist, ermöglichte die Integration des ähnlich strukturierten böhmischen Herzogtums in einen von Rang und Autorität geprägten Herrschaftsverband, dessen Oberhaupt eine besondere religiöse Legitimation für sich beanspruchte. Dieses Herzogtum ist zudem in mancher Hinsicht den übrigen Herzogtümern vergleichbar gewesen (nämlich hinsichtlich der königlichen Kirchenhoheit und der Mitwirkung des Königs bei der Herrschaftsnachfolge), wenn es auch in anderer Hinsicht deutliche Unterschiede aufweist (durch die Tributpflicht und das Fehlen von Reichsgut). Der ethnische Unterschied hingegen fiel weniger ins Gewicht. Auch in anderen Herzogtümern des Reiches, die schon längst nicht mehr als Stammesherzogtümer begriffen werden ${ }^{94}$, ließen sich ja nichtgermanische Ethnien finden: Romanen etwa in Lothringen und Bayern, Slawen in Kärnten. Und blickt man auf das Imperium, dann verstärkt sich der romanische Anteil noch weiter: durch die Herrschaft über Italien seit der Mitte des 10. Jahrhunderts und seit 1032 durch die Herrschaft über Burgund. Im engeren Reichsverband war allenfalls das Übergewicht einer nichtgermanischen Bevölkerung in einem Herzogtum ungewöhnlich, doch wird man davon ausgehen dürfen, dass die weltliche wie geistliche Führungsschicht in Böhmen zu großen Teilen des Theodisken mächtig war ${ }^{95}$. Konflikte zwischen dem böhmischen Herzog und dem König erwuchsen jedenfalls nicht aus ethnischen Differenzen, sondern wie bei den übrigen Herzögen auch aus Gegensätzen fürstlicher Interessen.

91 Vgl. Anm. 85.

92 Vgl. HOFFMANN, Böhmen und das deutsche Reich im hohen Mittelalter, S. 47, und František GRAUS, Böhmen im 9. bis 11. Jahrhundert (Von der „Stammesgesellschaft“ zum mittelalterlichen „Staat"), in: Gli slavi occidentali e meridionali nell'alto medioevo. Bd. 1. Spoleto 1983, S. 169-196, bes. $177 \mathrm{f}$.

93 Vgl. etwa Gerd ALTHOFF, Die Billunger in der Salierzeit, in: Stefan Weinfurter (Hg.), Die Salier und das Reich. Bd. 1: Salier, Adel und Reichsverfassung. Sigmaringen ${ }^{2} 1992$, S. 309-329, bes. 309; Hans-Werner GOETZ, Das Herzogtum im Spiegel der salierzeitlichen Geschichtsschreibung, ebd. S. 253-271, bes. 270 .

94 Vgl. ERKENS. Herzog, Herzogtum, S. 997.

95 Vgl. MORAW, Das Mittelalter, S. 47 f. und 49. 
Solche Gegensätze gründeten offenkundig auch in dem böhmischen Interesse, sich der ottonisch-salischen Oberhoheit zu entziehen und damit die zweifellos lästige Pflicht zur Tributzahlung abzustreifen; und natürlich führten sie regelmäßig zu militärischen Aktivitäten, die letztlich aber immer den Status quo bekräftigten. Nicht jeder Konflikt stand jedoch im Zeichen einer Loslösung vom Reich. Die Unterstützung etwa, die Boleslav II. Heinrich dem Zänker, dem Liudolfinger aus der bayerischen Herzogslinie, um 975 eine Zeit lang gegen den kaiserlichen, aber, was vielleicht nicht übersehen werden sollte, noch söhnelosen Vetter Otto II. und nach dessen Tod ( $†$ 983) im Ringen um die Herrschaft im Reich erneut, wenn auch offenbar zurückhaltender gewährte ${ }^{96}$, diese Unterstützung basierte letztlich auf einer Entscheidung, die eine Wahl darstellte zwischen zwei Rivalen aus dem regierenden Haus, eine Parteinahme mithin aus politischem Kalkül, wie sie jeder Herzog des Reichs ergreifen konnte, und nicht zwingend eine Distanzierung vom Reichsverband. Außerdem dürfte die königliche Oberhoheit nicht ausschließlich als Belastung empfunden worden sein. Schon allein die intensive Unterstützung, die Salier und Staufer von den přemyslidischen Herzögen erhielten, belegt dies ${ }^{97}$. Offenkundig profitierten nämlich auch die Přemysliden (und nicht nur die Beherrscher des Reiches) von einer Anlehnung an das Königtum.

In Böhmen waren während des 10. Jahrhunderts die Herrschaftsstrukturen - wie bereits erwähnt - deutlich weniger verfestigt als im Reich. Die Přemysliden waren zwar seit dem ausgehenden 9. Jahrhundert erkennbar aus der Masse der übrigen böhmischen Fürsten herausgewachsen und hatten sich an der Spitze des Herzogtums etabliert; völlig ungefährdet waren sie dort aber noch nicht. Vor allem in den Slavnikiden, zu denen auch Adalbert von Prag zählte, besaßen sie eine als gefährlich empfundene Konkurrenz - und zwar unabhängig davon, ob die Slavnikiden eine alte, schon lange mit den Přemysliden konkurrierende Fürstenfamilie gewesen ist, wie bislang meist angenommen wurde ${ }^{98}$, oder ob sie erst als Verwandte und im Gefolge der přemyslidischen Herzöge aufstiegen ${ }^{99}$ und von diesen schließlich als Bedrohung angesehen wurden. Der gleichnamige Sohn Boleslavs I. (des Brudermörders, der nicht zimperlich mit seinen Widersachern umging und „alle nicht přemyslidischen Fürsten“, wie einmal lakonisch festgestellt wurde ${ }^{100}$, „liquidierte“), Boleslav II., zeigte diese väterliche Härte 995 auch gegenüber den Slavniki-

${ }^{96}$ Vgl. Die Regesten des Kaiserreiches unter Otto II. 955 (973)-983, neubearb. von Hanns Leo MIKOLETZKY (= J. F. Böhmer, Regesta Imperii II. Sächsisches Haus: 919-1024, 2. Abt.). Graz 1950, Nr. 667b. 685a. 724b. 750a/b. 763c, und Die Regesten des Kaiserreiches unter Otto III. 980 (983)-1002, neubearb. von Mathilde UHLIRZ (= J. F. Böhmer, Regesta Imperii II. Sächsisches Haus: 919-1024, 3. Abt.). Graz/Köln 1956, Nr. 956 h1 / t1 / g2 / h2 / 12 / t2. 980b, und dazu SLÁMA, Der böhmische Fürst Boleslav II., S. 29, 31 und 34; HILSCH, Der Bischof von Prag, S. 14 f. und 18; ERKENS, Fürstliche Opposition, S. 338-346 und hier vor allem 340 ff., sowie DERS., ... more Grecorum conregnantem instituere vultis? Zur Legitimation der Regentschaft Heinrichs des Zänkers im Thronstreit von 984, in: FMS 27 (1993), S. 273-289.

97 Vgl. dazu HOFFMANN, Böhmen und das deutsche Reich im hohen Mittelalter, S. 58-61.

98 Vgl. etwa Johann LOSERTH, Der Sturz des Hauses Slawnik. Ein Beitrag zur Geschichte der Ausbildung des böhmischen Herzogthums, in: AÖG 65 (1884), S. 19-54; GRAUS, Böhmen im 9. bis 11. Jahrhundert, S. $173 \mathrm{ff}$., oder MORAW, Das Mittelalter, S. 43.

${ }^{99}$ Vgl. Dušan TŘEŠTÍK, Slavnikiden, in: Lexikon des Mittelalters 7 (1995), Sp. 2004. Zu der inneren Entwicklung Böhmens vgl. jetzt auch David KALHOUS, Anatomy of a Duchy. the Political and Ecclesiastical Structures of Early Přremyslid Bohemia. Leiden/Boston 2012, sowie dessen neu veröffentlichte Habilitationsschrift Bohemi. Prozesse der Identitätsbildung in frühpřemyslidischen Ländern (bis 1200), Wien 2018.

100 SLÁMA, Der böhmische Fürst Boleslav II., S. 25. 
den, deren Burg Libice er 995 trotz vereinbarten Waffenstillstands belagern ließ und die, soweit sie bei der Eroberung in seine Hände gefallen waren, niedergemacht wurden ${ }^{101}$. Seither gab es in Böhmen keine ernsthafte Konkurrenz mehr für die Přemysliden. Davor jedoch, aber auch künftig in tatsächlichen oder nur vermeintlichen Schwächephasen Rückhalt am Reich zu haben, war allerdings nicht unwichtig und half bei der Stabilisierung der přemyslidischen Herrschaft, etwa durch direkte Eingriffe der Reichsgewalt in Böhmen wie sie wenige Jahre nach der praktischen Ausrottung der Slavnikiden geschah bei der Vertreibung des polnischen Herzogs Bolesław Chrobry, der die Herrschaft über Böhmen anstrebte, oder bei Rivalitäten innerhalb der Herzogsfamilie ${ }^{102}$.

Im weiteren Verlauf der Geschichte bewirkten die sich intensivierende Integration Böhmens in das Reich und die starke Orientierung der Herzöge an der Reichsherrschaft den Aufstieg zweier Přemysliden zur Königswürde und schließlich die Erhebung des Herzogtums zum Königreich, dessen Oberhaupt zu einem angesehenen Fürsten des Reichs und zu einem der wenigen Königswähler avancierte und schließlich sogar selbst, allerdings erst nach dem Aussterben der Přemysliden, bis an die Spitze des Reiches aufsteigen konnte. Dies wäre (die beiden für das Reich bedeutungslos gebliebenen Könige des Interregnums aus dem Ausland können hier unberücksichtigt bleiben) für einen nicht dem Reich angehörenden Fürsten kaum möglich gewesen, denn auch Sigismund von Ungarn ist 1410 nicht als ungarischer König zum Herrscher im Reich gewählt worden, sondern als Sohn Karls IV. und Inhaber der brandenburgischen Kurwürde. Auf die gesamte Geschichte des Mittelalters gesehen ist der Nutzen, den die Herrscher Böhmens aus der engen Verbindung mit dem Reich zogen also keinesfalls gering gewesen, wenn dies um die erste Jahrtausendwende auch nicht absehbar war, die Oberhoheit der Ottonen und Salier zumindest zeitweise als Last empfunden worden ist und der Profit des fränkisch-deutschen Königs zumindest anfänglich größer war als der des böhmischen Herzogs.

\section{LITERATURVERZEICHNIS}

\section{Quellen}

Les Annales de Flodoard, hg. von Philippe LAUER. Paris 1905.

Annales de Saint-Bertin, hg. von Félix GRAT - Jeanne VIELLIARD - Suzanne CLÉMENCET. Paris 1964.

Annales Altahenses maiores, hg. von Edmund VON OEFELE (MGH Scriptores rerum Germanicarum in usum scholarum separatim editi. Bd. 4). Hannover 1891.

Annales Fuldenses sive Annales regni Francorum orientalis, hg. von Friedrich KURZE (MGH Scriptores rerum Germanicarum in usum scholarum separatim editi. Bd. 7). Hannover 1891.

Annales Magdeburgenses, hg. von Georg Heinrich PERTZ u. a., in: MGH Scriptores (in Folio). Bd. 16: Historiae aevi Suevici. Hannover 1859, S. 105-196.

Annales regni Francorum inde ab a. 741. usque ad a. 829, qui dicuntur Annales Laurissenses maiores et Einhardi, hg. von Friedrich KURZE (MGH Scriptores rerum Germanicarum in usum scholarum separatim editi. Bd. 6). Hannover 1895.

Bohemia-Moravia pontificia vel etiam Germania pontificia. Bd. 5, Teil 3: Provincia Maguntinensis. Teil 7: Dioeceses Pragensis et Olomocensis, hg. von Waldemar KÖNIGSHAUS. Göttingen 2011.

Die Chronik der Böhmen des Cosmas von Prag (Cosmae Pragensis Chronica Boemorum) (Scriptores rerum Germanicarum. Nova series 2), hg. von Berthold BRETZHOLZ. Berlin 1923.

${ }^{101}$ Vgl. ebd. S. 38 f. sowie HILSCH, Der Bischof von Prag, S. 24 f.

102 Vgl. Anm. 52 und 70 sowie MORAW, Das Mittelalter, S. 31. 
Continuatio Reginonis, hg. von Friedrich KURZE, in: Reginonis abbatis Prumiensis Chronicon cum continuatione Treverensi (MGH Scriptores rerum Germanicarum in usum scholarum separatim editi. Bd. 50). Hannover 1890, S. 154-179.

Einhardi Vita Karoli Magni, hg. von Oswald HOLDER-EGGER (MGH Scriptores rerum Germanicarum in usum scholarum separatim editi. Bd. 25). Hannover/Leipzig 1911.

Die Fälschungen Pilgrims von Passau. Historisch-kritische Untersuchung und Edition nach dem Codex Gottwicensis 53a (rot), 56 (schwarz), bearb. und hg. von Franz-Reiner ERKENS. München 2011.

Germania pontificia. Bd. 4: Provincia Maguntinensis. Teil 4: S. Bonifatius, archidioecesis Maguntinensis, abbatial Fuldensis, hg. von Hermann JAKOBS. Göttingen 1978.

Ordo ad regem benedicendum quando novus a clero et populo sublimatur in regem, hg. von Cyrille Vogel - Reinhard Elze, Le Pontifical romano-germanique du dixième siècle. Bd. 1: Le Texte. Città del Vaticano 1963.

Quellen zur deutschen Verfassungs-, Wirtschafts- und Sozialgeschichte bis 1250, hg. von Lorenz WEINRICH. Darmstadt 1977.

Die Reichschronik des Annalista Saxo, hg. von Klaus NASS (Scriptores (in Folio). Bd. 37). Hannover 2006.

Thietmari Merseburgensis episcopi Chronicon (Scriptores rerum Germanicarum. Nova series 9), hg. von Robert HOLTZMANN. Berlin 1935.

Die Urkunden Friedrichs II. 1212-1217, bearb. von Walter KOCH unter Mitwirkung von Klaus HÖFLINGER - Joachim SPIEGEL - Christian FRIEDL (MGH Die Urkunden der deutschen Könige und Kaiser. Bd. 14. Teil. 2). Hannover 2007.

Die Urkunden Heinrichs II. und Arduins, hg. von Harry BRESSLAU u. a. (MGH Die Urkunden der deutschen Könige und Kaiser. Bd. 3). Berlin 1900-1903.

Die Urkunden Heinrichs IV. Teil 3, bearb. von Alfred GAWLIK (MGH Die Urkunden der deutschen Könige und Kaiser. Bd. 6). Hannover 1978.

Die Urkunden Philipps von Schwaben, bearb. von Andrea RZIHACEK - Renate SPREITZER unter Mitwirkung von Brigitte MERTA - Christine OTTNER-DIESENBERGER (Die Urkunden der deutschen Könige und Kaiser. Bd. 12). Wiesbaden 2014.

Urkundenbuch des Stifts St. Peter und Alexander zu Aschaffenburg. Bd. 1: 861-1325, bearb. von Matthias THIEL. Aschaffenburg 1986.

Widukindi monachi Corbeienses Rerum gestarum Saxonicarum libri III, in Verbindung mit H.-E. Lohmann neu bearb. von Paul HIRSCH - Hans-Eberhard LOHMANN (MGH Scriptores rerum Germanicarum in usum scholarum separatim editi. Bd. 60). Hannover 1935.

\section{Literatur}

Stuart Airlie - Walter Pohl - Helmut Reimitz (Hgg.), Staat im frühen Mittelalter. Wien 2006.

Gerd ALTHOFF, Die Billunger in der Salierzeit, in: Stefan Weinfurter (Hg.), Die Salier und das Reich. Bd. 1: Salier, Adel und Reichsverfassung. Sigmaringen 1992, S. 309-329.

Gerd ALTHOFF, Das hochmittelalterliche Königtum. Akzente einer unabgeschlossenen Neubewertung, in: FMS 45 (2011), S. 77-98.

Gerd ALTHOFF, Kontrolle der Macht. Formen und Regeln politischer Beratung im Mittelalter. Darmstadt 2016.

Gerd ALTHOFF, Otto III. und die neuen Reiche im Osten, in: Gerd ALTHOFF - Hagen KELLER, Die Zeit der späten Karolinger und der Ottonen. Krisen und Konsolidierungen 888-1024. Stuttgart 2008, S. 295-303.

Gerd ALTHOFF, Die Ottonen. Königsherrschaft ohne Staat. Stuttgart 2000.

Gerd ALTHOFF, Das Privileg der, Deditio؛ Formen gütlicher Konfliktbeendigung in der mittelalterlichen Adelsgesellschaft, in: Gerd ALTHOFF, Spielregeln der Politik im Mittelalter. Kommunikation in Frieden und Fehde. Darmstadt 2014, S. 99-125 [erstmals 1997].

Gerd ALTHOFF, Spielregeln der Politik im Mittelalter. Kommunikation in Frieden und Fehde. Darmstadt 2014.

Gerd ALTHOFF, Spielregeln symbolischer Kommunikation und das Problem der Ambiguität, in: Barbara Stollberg-Rilinger u. a. (Hgg.), Alles nur symbolisch? Bilanz und Perspektiven der Erforschung symbolischer Kommunikation. Köln/Weimar/Wien 2013, S. 35-51. 
Gerd ALTHOFF - Hagen KELLER, Die Zeit der späten Karolinger und der Ottonen. Krisen und Konsolidierungen 888-1024. Stuttgart 2008.

Heinrich APPELT, Böhmische Königswürde und staufisches Kaisertum, in: DERS., Kaisertum, Königtum, Landesherrschaft. Gesammelte Schriften zur mittelalterlichen Verfassungsgeschichte, hg. von Othmar Hageneder - Herwig Wolfram. Wien 1988, S. 40-60 [erstmals 1972].

Adolf BACHMANN, Geschichte Böhmens. Bd. 1: bis 1400. Gotha 1899.

Matthias BECHER, Die subiectio principum: zum Charakter der Huldigung im Franken- und Ostfrankenreich bis zum Beginn des 11. Jahrhunderts, in: Stuart Airlie - Walter Pohl - Helmut Reimitz (Hgg.), Staat im frühen Mittelalter. Wien 2006, S. 163-178.

Tina BODE, König und Bischof in ottonischer Zeit. Herrschaftspraxis - Handlungsspielräume - Interaktionen. Husum 2015.

Eberhard BOHM, Elb- und Ostseeslaven, in: Lexikon des Mittelalters. Bd. 3. München 1986, Sp. 17791788.

Egon BOSHOF, Mainz, Böhmen und das Reich im Früh- und Hochmittelalter, in: Archiv für mittelrheinische Kirchengeschichte 50 (1998), S. 11-40.

Egon BOSHOF, Das ostfränkische Reich und die Slawenmission im 9. Jahrhundert, in: Franz-Reiner Erkens (Hg.), Königtum, Kirche und Mission im Südosten des Reiches. Ausgewählte Aufsätze von Egon Boshof. Festgabe zum 75. Geburtstag. Passau 2012, S. 33-60 [erstmals 1997].

Egon BOSHOF, Die Passauer Mission, in: Franz-Reiner Erkens (Hg.), Königtum, Kirche und Mission im Südosten des Reiches. Ausgewählte Aufsätze von Egon Boshof. Festgabe zum 75. Geburtstag. Passau 2012, S. 25-31 [erstmals 1997].

Harry BRESSLAU, Jahrbücher des Deutschen Reichs unter Konrad II. Bd. 1: 1024-1031. Leipzig 1879.

Harry BRESSLAU, Jahrbücher des Deutschen Reichs unter Konrad II. Bd. 2: 1032-1039. Leipzig 1884.

Carlrichard BRÜHL, Deutschland - Frankreich. Die Geburt zweier Völker. Köln/Wien 1995.

Wolfgang BRÜSKE, Untersuchungen zur Geschichte des Lutizenbundes. Deutsch-wendische Beziehungen des 10.-12. Jahrhunderts. Köln/Wien 1983.

Heinrich BÜTTNER, Erzbischof Willigis von Mainz und das Papsttum bei der Bistumserrichtung in Böhmen und Mähren im 10. Jh., in: Rhein. Vierteljahrsblätter 30 (1965), S. 1-22.

Jürgen Dendorfer - Roman Deutinger (Hgg.), Das Lehnswesen im Hochmittelalter. Forschungskonstrukte - Quellenbefunde - Deutungsrelevanz. Ostfildern 2010.

Roman DEUTINGER, Kaiser und Papst. Friedrich I. und Hadrian IV., in: Ders. - Jürgen Dendorfer (Hgg.), Das Lehnswesen im Hochmittelalter: Forschungskonstrukte - Quellenbefunde - Deutungsrelevanz. Ostfildern 2010, S. 329-345.

Joachim EHLERS, Die Entstehung des deutschen Reiches. München 2012.

Franz-Reiner ERKENS, Die ältesten Passauer Bischofsurkunden, in: ZBLG 46 (1983), S. 469-514.

Franz-Reiner ERKENS, Frommer Mönchskönig, sakraler Christusvikar und heiliger Kaiser Heinrich II., in: Norbert Jung - Holger Kempkens (Hgg.), Gekrönt auf Erden und im Himmel. Das heilige Kaiserpaar Heinrich II. und Kunigunde. Münsterschwarzach 2014, S. 20-27.

Franz-Reiner ERKENS, Fürstliche Opposition in ottonisch-salischer Zeit. Überlegungen zum Problem der Krise des frühmittelalterlichen Reiches, in: Archiv für Kulturgeschichte 64 (1982), S. 307-370.

Franz-Reiner ERKENS, Herrschersakralität im Mittelalter. Von den Anfängen bis zum Investiturstreit. Stuttgart 2006.

Franz-Reiner ERKENS, Herzog, Herzogtum, in: Handwörterbuch zur deutschen Rechtsgeschichte 2 (2011), S. 993-1004.

Franz-Reiner ERKENS, König, in: Handwörterbuch zur deutschen Rechtsgeschichte 3 (2013), S. 3-18.

Franz-Reiner ERKENS, Konrad II. Herrschaft und Reich des ersten Salierkaisers. Darmstadt 1998.

Franz-Rainer ERKENS, ... more Grecorum conregnantem instituere vultis? Zur Legitimation der Regentschaft Heinrichs des Zänkers im Thronstreit von 984, in: FMS 27 (1993), S. 273-289.

Franz-Reiner ERKENS, „Nach Art der himmlischen Martha“. Bischof Meinwerk im Dienst des Königs, in: Christoph Stiegemann - Martin Kroker (Hgg.), Für Königtum und Himmelreich. 1000 Jahre Bischof Meinwerk von Paderborn. Regensburg 2009, S. 58-73.

Franz-Reiner ERKENS, Die Salzburger Kirchenprovinz und das Bistum Augsburg im Zeitalter der Ottonen und der frühen Salier (907-1046), in: Walter Brandmüller (Hg.), Handbuch der bayerischen 
Kirchengeschichte. Bd. 1: Von den Anfängen bis zur Schwelle der Neuzeit 1. Kirche, Staat und Gesellschaft. St. Ottilien 1998, S. 133-186.

Zdeněk FIALA, Die Urkunde Friedrichs I. für den böhmischen Fürsten Vladislav II. vom 18. I. 1158 und das „Privilegium minus“ für Österreich, in: MIÖG 78 (1970), S. 167-192.

Wolfgang H. FRITZE, Corona regni Bohemiae. Die Entstehung des böhmischen Königtums im 12. Jahrhundert im Widerspiel von Kaiser, Fürst und Adel, in: DERS., Frühzeit zwischen Ostsee und Donau. Ausgewählte Beiträge zum geschichtlichen Werden im östlichen Mitteleuropa vom 6. bis zum 13. Jahrhundert, hg. von Ludolf Kuchenbuch und Winfried Schich. Berlin 1982, S. 207-296.

Wolfgang H. FRITZE, Das Vordringen deutscher Herrschaft in Teltow und Barnim, in: DERS., Frühzeit zwischen Ostsee und Donau. Ausgewählte Beiträge zum geschichtlichen Werden im östlichen Mitteleuropa vom 6. bis zum 13. Jahrhundert, hg. von Ludolf Kuchenbuch und Winfried Schich. Berlin 1982, S. 295-374 [erstmals 1971].

Hans-Werner GOETZ, Das Herzogtum im Spiegel der salierzeitlichen Geschichtsschreibung, in: Stefan Weinfurter (Hg.), Die Salier und das Reich. Bd. 1: Salier, Adel und Reichsverfassung. Sigmaringen 1992, S. 253-271.

František GRAUS, Böhmen im 9. bis 11. Jahrhundert (Von der „Stammesgesellschaft“ zum mittelalterlichen „Staat“), in: Gli slavi occidentali e meridionali nellalto medioevo. Bd. 1. Spoleto 1983, S. 169-196.

František GRAUS, Böhmen zwischen Bayern und Sachsen. Zur böhmischen Kirchengeschichte des 10. Jahrhunderts, in: Historica 17 (1969), S. 5-42.

Dieter HÄGERMANN, Karl der Große. Herrscher des Abendlandes. München 2000.

Wilfried HARTMANN, Karl der Große. Stuttgart 2010.

Wilfried HARTMANN, Ludwig der Deutsche. Darmstadt 2002.

Werner HECHBERGER, Adel im fränkisch-deutschen Mittelalter. Zur Anatomie eines Forschungsproblems. Ostfildern 2005.

Werner HECHBERGER, Adel, Ministerialität und Rittertum im Mittelalter. München 2004.

Ernst-Dieter HEHL, Die Mainzer Kirche in ottonisch-salischer Zeit (911-1122), in: Friedhelm Jürgensmeier (Hg.), Handbuch der Mainzer Kirchengeschichte. Bd. 1/1: Christliche Antike und Mittelalter. Würzburg 2000, S. 195-280.

Walter HEINEMEYER, „beneficium - non feudum sed bonum factum“. Der Streit auf dem Reichstag zu Besançon 1157, in: Archiv für Diplomatik 15 (1969), S. 155-236.

Peter HILSCH, Der Bischof von Prag und das Reich in sächsischer Zeit, in: DA 28 (1972), S. 1-41.

Siegfried HIRSCH, Jahrbücher des Deutschen Reiches unter Heinrich II. Bd. 1. Berlin 1862 und Bd. 2, vollendet von Hermann PABST. Berlin 1864.

Ivan HLAVÁČEK, Die Itinerare der böhmischen Herrscher bis zum Jahre 1253 aus verwaltungsgeschichtlicher Sicht, in: Sáša Dušková (Hg.), Folia Diplomatica. Bd. 1. Brno 1971, S. 113-127.

Jörg K. HOENSCH, Geschichte Polens. Stuttgart 1998.

Hartmut HOFFMANN, Mönchskönig und „rex idiota“. Studien zur Kirchenpolitik Heinrichs II. und Konrads II. Hannover 1993.

Die Jahrbücher des Fränkischen Reiches unter Karl dem Großen, hg. von Sigurd ABEL, fortgesetzt von Bernhard SIMSON. Bd. 2: 789-814. Leipzig 1883.

David KALHOUS, Anatomy of a Duchy. The Political and Ecclesiastical Structures of Early Premyslid Bohemia. Leiden/Boston 2012.

David KALHOUS, Bohemi. Prozesse der Identitätsbildung in frühprememyslidischen Ländern (bis 1200), Wien 2018.

Brigitte KASTEN, Beneficium zwischen Landleihe und Lehen - eine alte Frage, neu gestellt, in: Dieter R. Bauer u. a. (Hgg.), Mönchtum - Kirche - Herrschaft. 750-1000. Sigmaringen 1998, S. 243-260.

Jiř́ KEJǨ, Böhmen und das Reich unter Friedrich I., in: Alfred Haverkamp (Hg.), Friedrich Barbarossa. Handlungsspielräume und Wirkungsweisen des staufischen Kaisers. Sigmaringen 1992, S. 240-289.

Johann LOSERTH, Der Sturz des Hauses Slawnik. Ein Beitrag zur Geschichte der Ausbildung des böhmischen Herzogthums, in: AÖG 65 (1884), S. 19-54.

Herbert LUDAT, Elbslaven und Elbmarken als Problem der europäischen Geschichte, in: DERS., Slaven und Deutsche im Mittelalter. Ausgewählte Aufsätze zu Fragen ihrer politischen, sozialen und kulturellen Beziehungen. Köln/Wien 1982, S. 1-13 [erstmals 1968].

Christian LÜBKE, Das östliche Europa. München 2004. 
Paul MAI, Bemerkungen zur Taufe der 14 böhmischen duces im Jahre 845, in: Beiträge zur Geschichte des Bistums Regensburg 29 (1995), S. 11-18.

Klaus-Peter MATSCHKE, Feudalismus ade? Ein Byzantinist liest S. Reynolds, in: Rechtshistorisches Journal 14 (1995), S. 87-92.

Ulrich MATTEJIET, Tribut III. Hoch- und Spätmittelalter, in: Lexikon des Mittelalters 8 (1997), Sp. 987.

Erich MEUTHEN, Das 15. Jahrhundert. München/Wien 1980.

Heinrich MITTEIS, Der Staat des hohen Mittelalters. Grundlinien einer vergleichenden Verfassungsgeschichte des Lehnszeitalters. Darmstadt 1974.

Peter MORAW, Das Mittelalter, in: Friedrich Prinz (Hg.), Deutsche Geschichte im Osten Europas. Böhmen und Mähren. Berlin 1993, S. 23-178.

Peter MORAW, Über König und Reich. Aufsätze zur deutschen Verfassungsgeschichte des späten Mittelalters, hg. von Rainer Christoph Schwinges. Sigmaringen 1995.

Peter MORAW, Von offener Verfassung zu gestalteter Verdichtung. Das Reich im späten Mittelalter. 1250 bis 1490. Berlin 1985.

Klaus NASS. Die Reichschronik des Annalista Saxo und die Geschichtsschreibung im 12. Jahrhundert. Hannover 1996.

Otto Gerhard OEXLE, Die Abschaffung des Feudalismus ist gescheitert, in: Frankfurter Allgemeine Zeitung Nr. 116 vom 19. Mai 1995.

Steffen PATZOLD, Das Lehnswesen. München 2012.

Walter Pohl - Veronika Wieser (Hgg.), Der frühmittelalterliche Staat - Europäische Perspektiven. Wien 2009.

Paul PRAXL, Das Alter des Goldenen Steiges, in: Ostbairische Grenzmarken 3 (1959), S. 112-123.

Paul PRAXL, Der Goldene Steig. Salzwege von Passau nach Böhmen, in: Manfred Treml u. a. (Hgg.). Salz Macht Geschichte. Aufsätze. Regensburg 1995, S. 332-340.

Die Regesten der Bischöfe von Passau. Bd. 1: 731-1206, bearb. von Egon BOSHOF. München 1992.

Die Regesten des Kaiserreichs unter Heinrich I. und Otto I. 919-973, neubearb. von Emil VON OTTENTHAL mit Ergänzungen von Hans H. KAMINSKY (= J. F. Böhmer, Regesta Imperii II. Sächsisches Haus 919-1024, 1. Abt.). Hildesheim 1967.

Die Regesten des Kaiserreiches unter Heinrich II. 1002-1024, neubearb. von Theodor GRAFF (= J. F. Böhmer, Regesta Imperii II. Sächsisches Haus: 919-1024, 4. Abt.). Wien 1971.

Die Regesten des Kaiserreiches unter Otto II. 955 (973)-983, neubearb. von Hanns Leo MIKOLETZKY (= J. F. Böhmer, Regesta Imperii II. Sächsisches Haus: 919-1024, 2. Abt.). Graz 1950.

Die Regesten des Kaiserreiches unter Otto III. 980 (983)-1002, neubearb. von Mathilde UHLIRZ (= J. F. Böhmer, Regesta Imperii II. Sächsisches Haus: 919-1024, 3. Abt.). Graz/Köln 1956.

Regesten zur Geschichte der Mainzer Erzbischöfe von Bonifatius bis Heinrich II. 742?-1288. Bd. 1: Von Bonifatius bis Arnold von Selehofen 742?-1160, bearb. und hg. von Cornelius Will. Innsbruck 1877.

Susan REYNOLDS, Fiefs and Vassals. The Medieval Evidence Reinterpreted. Oxford 1994.

Gotthold RHODE, Kleine Geschichte Polens. Darmstadt 1965.

Rudolf SCHIEFFER, Christianisierung und Reichsbildungen. Europa 700-1200. München 2013.

Bernd SCHNEIDMÜLLER, Konsensuale Herrschaft. Ein Essay über Formen und Konzepte politischer Ordnung im Mittelalter, in: Paul-Joachim Heinig u. a. (Hgg.), Reich, Regionen und Europa in Mittelalter und Neuzeit. Festschrift für Peter Moraw. Berlin 2000, S. 53-87.

Percy Ernst SCHRAMM, Böhmen und das Regnum. Die Verleihungen der Königswürde an die Herzöge von Böhmen (1085/86, 1158, 1198/1203), in: DERS., Kaiser, Könige und Päpste. Gesammelte Aufsätze zur Geschichte des Mittelalters. Bd. 4. Teil 2. Stuttgart 1971, S. 517-539 [erstmals 1956].

Percy Ernst SCHRAMM, Das polnische Königtum. Ein Längsschnitt durch die polnische Geschichte (im Hinblick auf Krönung, Herrschaftszeichen und Staatssymbolik), in: DERS., Kaiser, Könige und Päpste. Gesammelte Aufsätze zur Geschichte des Mittelalters. Bd. 4. Teil 2. Stuttgart 1971, S. 570-596 [erstmals 1956].

Josef SEMMLER, Francia Saxoniaque oder Die ostfränkische Reichsteilung von 865/76 und die Folgen, in: DA 46 (1990), S. 337-374.

Jiří SLÁMA, Der böhmische Fürst Boleslav II., in: Petr Sommer (Hg.), Boleslav II. Der tschechische Staat um das Jahr 1000. Praha 2001, S. 15-42. 
Dušan TŘEŠTíK, Großmähren, Passau und die Ungarn um das Jahr 900. Zu den neuen Zweifeln an der Authorizität des Briefes der bayerischen Bischöfe an Papst Johann IX. aus dem Jahr 900, in: Byzantinoslavica 59 (1998), S. 137-160.

Dušan TřEŠTÍK, Slavnikiden, in: Lexikon des Mittelalters 7 (1995), Sp. 2004.

Thomas VON BOGYAY, Grundzüge der Geschichte Ungarns. Darmstadt 1977.

Georg WAITZ, Deutsche Verfassungsgeschichte. Bd.8: Die deutsche Reichsverfassung von der Mitte des neunten bis zur Mitte des zwölften Jahrhunderts. Kiel 1878.

Stefan WEINFURTER, Karl der Große. Der heilige Barbar. München/Zürich 2013.

Stefan WEINFURTER, Kollegen des Königs. Die Bischöfe im Reich vor 1000 Jahren, in: Christoph Stiegemann - Martin Kroker (Hgg.), Für Königtum und Himmelreich. 1000 Jahre Bischof Meinwerk von Paderborn. Regensburg 2009, S. 30-38.

Martin WIHODA, Die Sizilischen Goldenen Bullen von 1212. Kaiser Friedrichs II. Privilegien für die Přemysliden im Erinnerungsdiskurs. Wien/Köln/Weimar 2012.

Herwig WOLFRAM, Grenzen und Räume. Geschichte Österreichs vor seiner Entstehung. Wien 1995.

Joachim WOLLASCH, Kaiser und Könige als Brüder der Mönche. Zum Herrscherbild in liturgischen Handschriften des 9. bis 11. Jahrhunderts, in: DA 40 (1984), S. 1-20.

Heinz WOLTER, Die Synoden im Reichsgebiet und in Reichsitalien von 916 bis 1056. Paderborn 1988.

Thomas WÜNSCH, Deutsche und Slawen im Mittelalter. Beziehungen zu Tschechen, Polen, Südslawen und Russen. München 2008.

Claudia ZEY, Der Investiturstreit. München 2017. 